\title{
Deposition processes and properties of coatings on steel fasteners - A review
}

\author{
Ping Ping CHUNG, James WANG, Yvonne DURANDET ${ }^{*}$ \\ Department of Mechanical and Product Design Engineering, Faculty of Science, Engineering and Technology, Swinburne University of \\ Technology, Hawthorn VIC. 3122, Australia \\ Received: 14 December 2018 / Revised: 15 January 2019 / Accepted: 16 May 2019 \\ (C) The author(s) 2019.
}

\begin{abstract}
Mechanical fastening is widely used in joining metals, particularly in automotive, aerospace, building and construction industries. However, the main concern on mechanical fastening is the issue of corrosion. An effective way to prolong the service life of steel fasteners is to apply protective coatings onto these components. This paper reviews and compares a few common coating deposition techniques, i.e., electroplating, hot-dip galvanizing, ion vapour deposition and mechanical plating, in terms of their characteristics. Compositional and microstructural properties including morphology and porosity, corrosion resistance performance and frictional performance of the coatings formed by each process are discussed in details. Hydrogen embrittlement, a premature failure often occurred on high strength steel fasteners, is also reviewed. The key results of recent studies of various metallic coatings on fasteners are presented to provide a fundamental understanding of the evolving topics, and the research gaps have been identified for further investigation.
\end{abstract}

Keywords: zinc coating; steel fasteners; frictional characteristics; corrosion performance; mechanical plating; electroplating

\section{Introduction}

Fasteners play an important role in the sustainability of both fixed and mobile infrastructures contributing long-term mechanical or structural integrity to assembled components and systems. For instance, coated fasteners must be able to provide service life of 30-50 years or more in the building and construction industry [1] and 10-20 years or more in the automotive industry [2]. The design and production of lightweight automotive structures has been one of the key strategies to address global sustainability challenges of reducing greenhouse gas emissions by vehicles [3]. Thus, new fastener and coating materials as well as new joining techniques are also being developed to enable the adoption of advanced lightweight materials such as high strength aluminium and magnesium alloys, ultrastrength steels, and hybrid composites [4-6].
Typical issues for steel fasteners during their service life are closely related to atmospheric corrosion, galvanic corrosion, crevice corrosion and hydrogen embrittlement (specifically on high strength steel). Contact of dissimilar materials, for example on the assembly of high strength steel fasteners and aluminium alloy sheets, in the presence of a conducting medium or electrolyte increases the risk of galvanic corrosion due to the huge difference of electrochemical potentials of these materials [7, 8]. Crevice corrosion, a localized attack on a metal surface at the crevice between two joining surfaces, usually occurs at the narrow gap between the fastener and metal sheets due to the difference between the electrolyte concentration within the crevice (depletion of oxygen) and outside the crevice (abundant of oxygen) [9]. Hydrogen embrittlement occurs when the high strength steel fastener is in tension and fails even though the applied stress is

* Corresponding author: Yvonne DURANDET, E-mail: ydurandet@swin.edu.au 
much less than the yield strength of the steel because of the presence of hydrogen [10]. It causes catastrophic brittle fracture, and therefore, hydrogen absorption is always a concern on high strength steel fasteners. To reduce the possibilities of various corrosions and achieve longer service life, surface coatings are usually applied to protect fasteners.

Surface coatings on steel fasteners are multifunctional, combining corrosion resistance with scratch resistance and excellent frictional characteristics to facilitate their insertion during assembly, especially on un-threaded fasteners used for joining-by forming such as rivets for self-pierce riveting. Also, both coating material and deposition process are expected to be environmentally friendly and cost effective. Typical metallic coatings on fasteners are cadmium, zinc, zinc-based alloy and aluminium, and are commonly applied using electroplating, hot-dip galvanizing, ion vapour deposition and mechanical plating.

This paper provides a comprehensive review of the key results of recent studies on existing techniques for depositing metallic coating on fasteners from the perspective of the process, structures, properties and ultimate performance of these coatings, and presents the current state of understanding of the evolving topics and knowledge gaps for further research.

\section{Protective coating deposition techniques}

\subsection{Electroplating}

\subsubsection{Electroplating process}

Electroplating has been the most popular and commonly used method for fastener coating deposition. It is an electrolytic process consisting of external circuit, cathode, anode and plating solution [11].

The two most commonly used electroplating processes are rack plating and barrel plating. Most fasteners are barrel-plated [12-14]. Its process is schematically illustrated in Fig. 1. Barrel plating consists of a cathode, which is the barrel that contains parts to be plated, and an anode, which is the plating material. Wires are connected to the cathode and the anode, forming an external circuit. The cathode and the anode are then connected to negative and positive terminal of the power supply, respectively. Both electrodes are

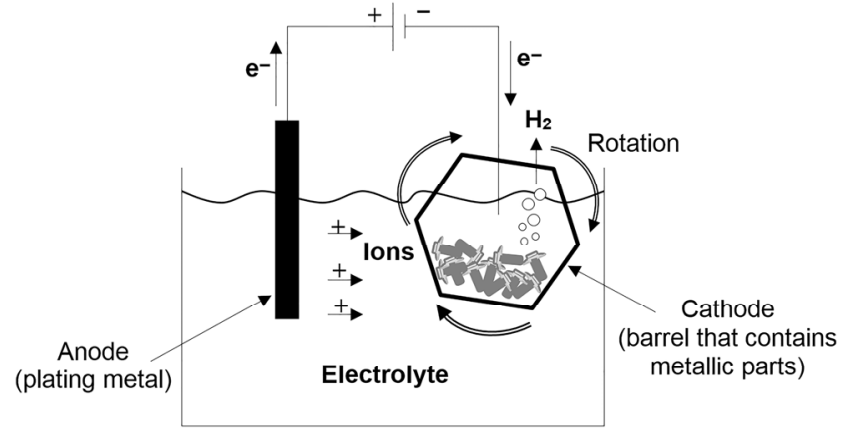

Fig. 1 Schematic of a simple barrel plating process.

immersed into the electrolyte, which allows the metal ions to migrate from the anode to the cathode. Oxidation reaction occurs at the anode, producing electrons that travel through the external circuit to the cathode.

$$
\mathrm{M} \rightarrow \mathrm{M}^{n+}+n \mathrm{e}^{-}
$$

While reduction occurs at the cathode when metal ions from the anode and/or the electrolyte migrate to the cathode, and then reduced to atoms by gaining electrons from the anode.

$$
\mathrm{M}^{n+}+n \mathrm{e}^{-} \rightarrow \mathrm{M}
$$

The barrel is being rotated in the plating bath throughout the plating process to expose evenly all the surfaces of fasteners and produce more uniform coatings compared to those rack-plated ones [14].

\subsubsection{Advantages and disadvantages of electroplating}

Electroplating is capable of depositing high performance alloy coatings such as Zn-Ni, Zn-Co, Zn-Sn [15] within a wide range of thickness values from $1 \mu \mathrm{m}$ up to $1 \mathrm{~mm}$ [16] with most coating thickness of 3-12 $\mu \mathrm{m}$ [17].

However, the major drawback of electroplating is the concurrent evolution of hydrogen at the cathode during electroplating [11]. As a result, any current devoted to hydrogen evolution at the cathode is considered wasted, resulting in low cathode current efficiency. Hydrogen evolution and permeation during zinc electroplating on steel occur in the initial stages when the steel surface has just been partially coated. The evolved hydrogen is predominantly dissipated to the atmosphere via gas bubbles at a constant rate with some distributed to the electrolyte while others diffused into the substrate [18]. In addition, some 
hydrogen may be trapped in the deposits before diffusing into the substrate [19]. Although the hydrogen permeation decreases with increasing the thickness of the zinc coating, the coating did not inhibit hydrogen from being trapped in the deposit. The diffused hydrogen produces some detrimental effects, such as reduction in ductility and loss in mechanical strength, leading to hydrogen embrittlement [10]. To avoid the deleterious effects of hydrogen embrittlement during zinc plating, some additives, such as Na-benzoat and polyethylene glycol were added to the plating baths to alter the hydrogen evolution and permeation process $[18,20]$.

In order to recover the mechanical properties, ASTM B850 [21] strongly recommends that post baking at 190-220 ${ }^{\circ} \mathrm{C}$ for at least 4-22 hours should be performed within 1 to 3 hours immediately after electroplating, depending on the tensile strength of the substrate. Since the risk of hydrogen embrittlement cannot be completely eliminated even by post baking, ASTM F1941 [17] further suggests that post baking is not mandatory for fasteners with hardness below $39 \mathrm{HRC}$, while fasteners with hardness of 39-44 HRC and over 44 HRC should be baked at $190-220^{\circ} \mathrm{C}$ for a minimum of 14 hours and 24 hours, respectively.

Most active metals such as aluminium and magnesium are precluded in aqueous-based electroplating systems due to the narrow electrochemical potential range [22], in which the electrolyte does neither get oxidized nor reduced at an electrode [23]. This narrow potential range is significant for the efficiency of an electrode; out of this range, water gets electrolysed, spoiling the electrical energy that is intended for another electrochemical reaction and causing the entire current to be used up for only hydrogen evolution. Ionic liquids, which are nonaqueous based electrolytes, are therefore being used to electroplate those active metals, such as aluminium, on fasteners [24].

Another drawback of electroplating by aqueous electrolytes is its potential toxicity. Cyanide baths, for example, are well-known toxic solutions that have been most widely used for zinc electroplating due to their good throwing power and high deposition rate $[16,25]$. As a result, waste disposal has always been a concern in electroplating industry, i.e., high rinse water and waste cost [16].

\subsection{Hot-dip galvanizing}

\subsubsection{Hot-dip galvanizing process}

Hot-dip galvanizing is a typical process to deposit zinc coatings on steel fasteners by immersing the fasteners into a bath of molten zinc. This process has been widely used mainly due to its economic value in producing effective corrosion protection on fasteners.

In hot-dip galvanizing, fasteners are cleaned by degreasing and then pickled by either sulphuric or hydrochloric acid [26, 27]. A flux coating is then applied to prevent the cleaned surface from oxidation and to prepare the wetting of the surface before immersing into the molten zinc bath. The molten zinc bath for conventional galvanizing is in a range of $435-480{ }^{\circ} \mathrm{C}$, however, if a smoother and thinner coating is required, the bath temperature can be increased to $530-560{ }^{\circ} \mathrm{C}$ [28]. The coating thickness is proportional to the immersion time into the bath, ranging typically from 3 to 6 minutes, while the uniformity of the coating depends greatly on the speed of the withdrawal from the immersion [27]. The bath temperature also influences the coating thickness formed. Kuklík and Kudláček [29] reported that for steel containing less than $0.03 \%$ silicon that is immersed for 5 minutes in the bath, coating thickness increases as the bath temperature increases up to $480{ }^{\circ} \mathrm{C}$, after which the relationship then becomes inversely proportional (Fig. 2(a)). The composition of silicon in steel affects the coating thickness evolution differently as the bath temperature changes. For steel containing more than $0.12 \%$ Si (Fig. 2(b)), the coating thickness reduces when the bath temperature is within the range of $440-470{ }^{\circ} \mathrm{C}$, but then increases proportionally at higher temperatures up to $500{ }^{\circ} \mathrm{C}$. Galvanized coating on fasteners is generally in the thickness range of 30 $60 \mu \mathrm{m}$. ASTM F2329 [28] and ASTM A153 [30] give the minimum zinc coating thickness required for various classes of fastener.

"Spin-galvanizing" is the galvanizing process that is typically used to galvanize small articles such as fasteners [26]. Fasteners are put into a chemically resistant plastic container for pre-treatment process [31]. After soaking and drying, the fasteners are then loaded into a cylindrical basket, followed by immersion into the zinc bath. After withdrawing from the molten bath, the basket is spun in centrifuge to remove excessive 


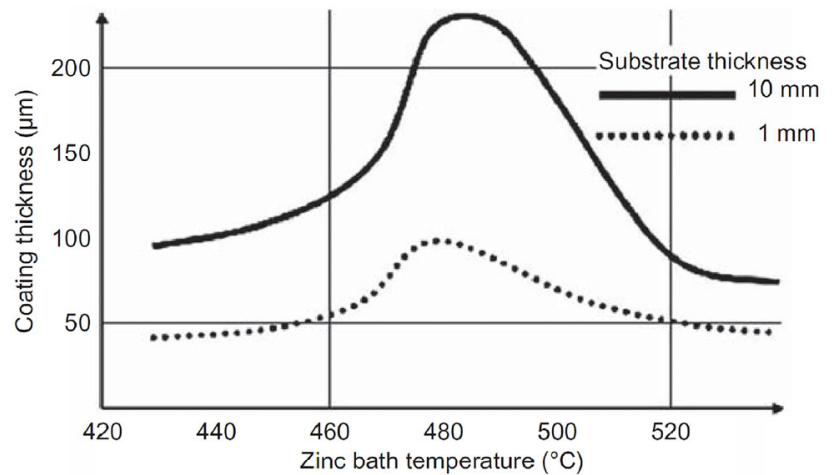

(a)

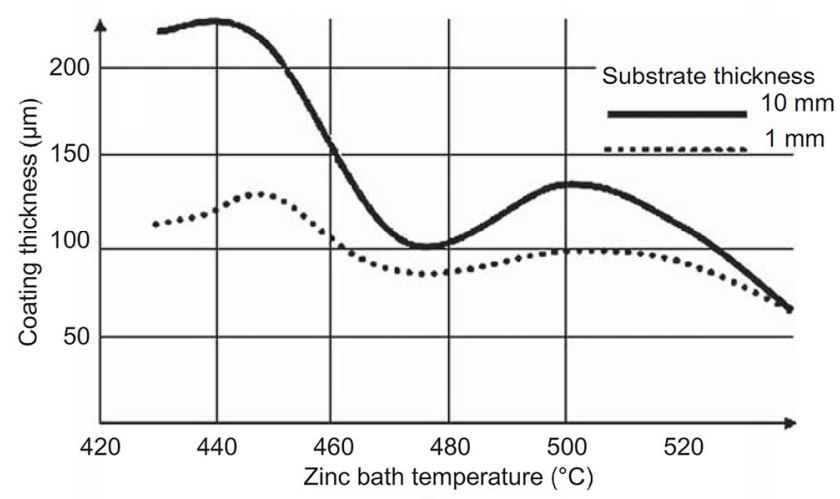

(b)

Fig. 2 Temperature-dependence of the coating thickness in hot-dip galvanizing with immersion time of 5 minutes for steel containing (a) $<0.03 \% \mathrm{Si}$ and (b) $>0.12 \% \mathrm{Si}$. Reproduced with permission from Ref. [29], (C) Elsevier, 2016.

zinc on the threads, leaving a uniform distribution of the coating. The coating then solidifies through air-cooled or water-quenched. Upon solidification, iron-zinc intermetallic phases, i.e. gamma $(\Gamma)$, delta $(\delta)$, and zeta $(\zeta)$, are formed.

Aluminium and tin can also be hot-dipped [26], but their application to fasteners is not as common as hot-dip zinc coating. These two elements are usually added into the molten zinc bath as an alloy to obtain improved performance of the hot-dip galvanized coatings. Generally less than $1 \mathrm{wt} . \% \mathrm{Al}$ is added into the bath for normal galvanized coating to control the formation of $\mathrm{Fe}-\mathrm{Zn}$ intermetallic phases, while Galfan and Galvalume are two major type of hot dip $\mathrm{Zn}-\mathrm{Al}$ coatings that consist of $5 \mathrm{wt} . \%$ and $55 \mathrm{wt} . \%$ of $\mathrm{Al}$, respectively [32].

\subsubsection{Advantages and disadvantages of hot-dip galvanizing}

Hot-dip galvanizing is a relatively economical process to deposit thick zinc coatings that provide excellent corrosion protection. However, the uneven coating thickness can be an issue, especially on threaded fasteners [33].

Like electroplating, hot-dip galvanizing also causes the risk of hydrogen embrittlement of fasteners [34, 35], especially for high strength steel with hardness of 33 HRC and above. It is generally believed that hydrogen is picked up during the acid pickling process and, therefore, baking is required after pickling and prior to galvanizing. However, threaded steel fasteners that have been heat treated to hardness of $40 \mathrm{HRC}$ and above are not recommended to be hot-dip galvanized [28].

Since hot-dip galvanizing is a high temperature process, it is therefore critical to ensure the mechanical properties of the fasteners are not affected adversely during the process, especially above $425^{\circ} \mathrm{C}$ [28].

Another concern with hot-dip galvanizing is the possible galvanization of high strength steels [36]. Selective oxidation, caused by the alloying elements in high strength steel, occurs on the surface of the steel during the annealing process. Increasing the dew point of annealing atmosphere will be able to improve the wetting by $\mathrm{Zn}$ [36], and cause changes in the subsurface microstructure, which may subsequently affect the mechanical properties of high strength steel [37]. An additional pre-oxidation treatment before annealing the high-manganese steel has enhanced the wetting behaviour of $\mathrm{Zn}$ during hot-dip galvanizing $[38,39]$ and the oxide layer formed cannot be removed and thus affecting the steel wettability for hot-dip zinc coatings.

\subsection{Ion vapour deposition}

\subsubsection{Ion vapour deposition process}

Ion vapour deposition, also known as ion plating, has been used to deposit aluminium coatings on aircraft and spacecraft fasteners as a green replacement to electroplated cadmium coatings, which is banned due to its toxicity $[40,41]$.

Ion vapour deposition (IVD) is based on the theory of ion bombardment onto the substrate in a vacuum environment. Figure 3 [42] illustrates the vacuum-based ion plating system using an ion gun for bombardment and electron-beam as evaporation source. The vacuum chamber is usually pumped down to $1.3 \mathrm{MPa}\left(10^{-5}\right.$ 
Torr), and then backfilled with an inert gas such as argon [43]. A high voltage is then applied to ionize the argon gas. The ions then bombard the surface of the negatively charged substrate, causing glow discharge which cleans the surface of the substrate continuously throughout the operation to ensure that the surface is not re-contaminated in order to yield outstanding adhesion [40,44]. At the same time, vapour source is also being ionized so that it can be attracted and condensed on the surface of the substrate [40]. The vapour source is from the electron beam gun or the evaporation of aluminium slug through heating the crucible [42]. The substrate is normally heated to $100-300{ }^{\circ} \mathrm{C}$, depending on the types of coating material [45]. Small components such as fasteners are commonly deposited in a barrel coater, which consists of vacuum chamber and pumping system [40, 46-47]. An apparatus called IVADIZER was invented by McDonnell Aircraft Company for aluminium ion vapour deposition, particularly on aircraft fasteners, by tumbling the barrel while maintaining the bombardment $[40,48]$.

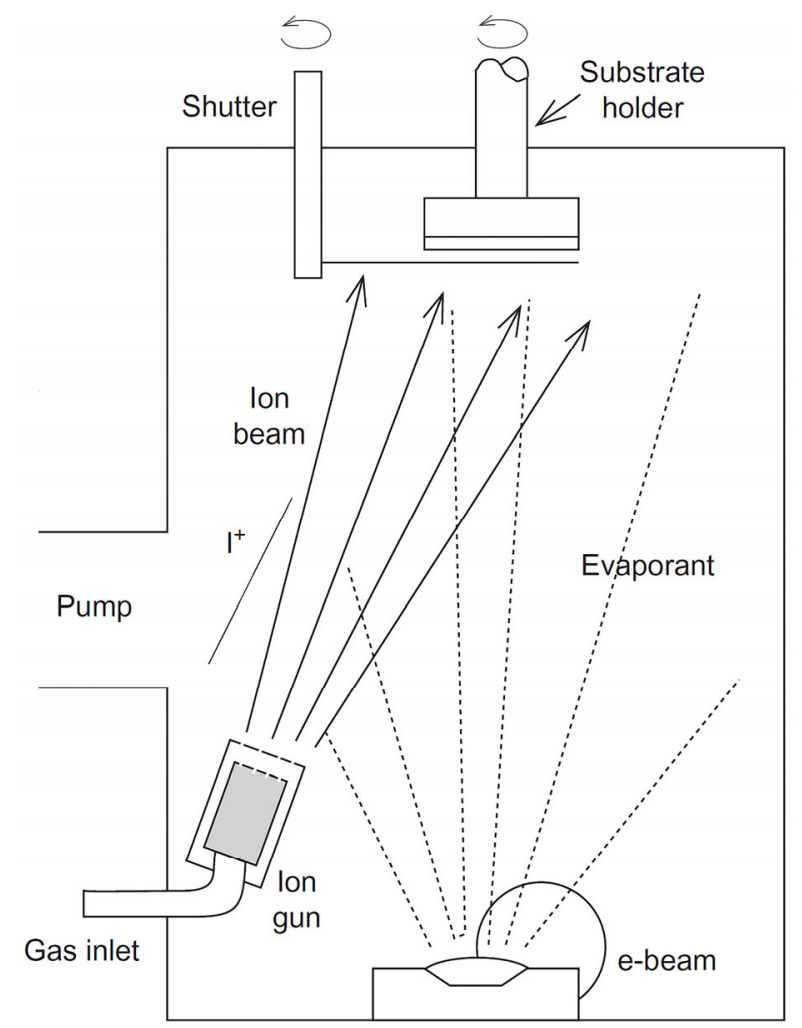

Fig. 3 Vacuum-based ion plating system using an ion gun for bombardment and electron-beam evaporation source. Reproduced with permission from Ref. [42], (C) Elsevier, 2010.
2.3.2 Advantages and disadvantages of ion vapour deposition

Ion vapour deposition is advantageous in depositing thin and adherent coatings that are distributed uniformly on the surface of the substrate [42]. The coating thickness of IVD aluminium is normally in the range of $8-25 \mu \mathrm{m}$. Thicker coatings $(>25 \mu \mathrm{m})$ can be deposited for applications in highly corrosive environments [49, 50]. McCune et al. [51] reported that thicker coating layers are possible to be deposited by increasing the treatment times. However, thick coatings did not exhibit any improvement against galvanic corrosion, while thin coatings $(<8 \mu \mathrm{m})$ are more applicable by IVD, but the corrosion resistant performance of such thin coatings has to be compromised [50].

Ion vapour deposition can eliminate the risk of hydrogen embrittlement on steel substrates, because the deposition process is completed in a hydrogen-free vacuum environment [40]. Fasteners used in aircrafts and spacecrafts are mainly high strength steels, which are commonly susceptible to hydrogen embrittlement, and hence ion vapour deposition is capable of eliminating such concerns, and further reducing the cost in the post-embrittlement relief baking operation. In addition, IVD aluminium coatings can be used at a service temperature up to $496^{\circ} \mathrm{C}$ without causing any adverse effect [40,41]. This is particularly significant when high service temperatures are required especially in aerospace industry.

Since ion vapour deposition process is operated in a vacuum condition, and no hazardous chemicals are involved, waste disposal has never been an issue [40, 41]. However, expensive investment in the equipment and comparatively low volume output are major factors that restrain its wide applications in industry [45].

\subsection{Mechanical plating}

\subsubsection{Mechanical plating process}

Mechanical plating, developed in 1950s and been commercially available since 1960s, is a process in which metallic coatings are deposited onto small metallic parts, such as fasteners, bolts, washers, hose clamps, and nails, etc., using kinetic energy at room temperature $[52,53]$. It is also known as peen plating or impact plating due to the fact that the coating is 
"cold-welded" or "peened" onto the surface of the substrates from the agitation of the barrel.

In mechanical plating, parts are placed into a tumbling barrel, along with the metal powders, glass beads, water and chemical promoters. Through the rotation or agitation of the barrel, impact from the glass beads causes the metal powders to peen or "cold-weld" together onto the surface of the parts, producing a layer of coating [54]. A typical mechanical plating process begins with surface preparation of the parts cleaned with mild acid [53]. A coppering solution is then added to form a thin copper flash as a base coat that promotes adhesion of the mechanical coating [55]. In addition, pre-plating with tin flash by adding tin salt prior to metal powder addition was also suggested [56]. The tin salt dissolves into the solution, tends to release electrons, reduces the positively charge ions of the plating metal, and results in the deposition of the plating metal on the substrate [56].

A promoter, which acts as a catalyst or accelerator, is added into the barrel to create a chemical environment that controls the rate of deposition and bonding strength of the plating metals [53]. Dry and fine metallic powders are then added into the barrel. Its amount determines the coating thickness, and both exhibit a directly proportional relationship. The thickness of the coating ranges from 5 to $75 \mu \mathrm{m}$ [53].

The $\mathrm{pH}$ values of the plating solutions have to be controlled within 1 to 2 in order to maintain an oxide free condition for the parts and the metal particles [53]. A complete cycle of mechanical plating process takes approximately 25-45 minutes, depending on the coating thickness [57]. Once the desired thickness has achieved, the parts will be fully rinsed with water, discharged from barrel and then the glass beads will be removed for reuse [55].

The process has $92 \%$ efficiency, which indicates that approximately $92 \%$ of the added metal powders are effectively plated on the parts [53]. The metal powders may also be added in the form of aqueous slurry for better coating uniformity [57]. The mechanical plating process depends greatly on the impact energy, which is transferred from either the glass beads, the metal particles or the adjacent parts [57]. As a result, the size of the glass beads, the ratio of glass beads to parts, the metal particles size, the barrel rotation speed and the barrel angle are important parameters to achieve quality coatings with a desired thickness $[53,57]$. The kinetic energy from the tumbling is transferred to the spherical particles and cause some of them to peen weld together, and therefore, the final shapes of the deposited metal particles are normally distorted, usually exhibiting flat or dish shapes [57].

\subsubsection{Advantages and disadvantages of mechanical plating}

Mechanical plating has been widely used in automotive industry on hardened steel parts, especially as an alternative to electroplating to eliminate the risk of hydrogen embrittlement [58]. Mechanical plating is energy efficient because it operates at room temperature. In addition, it does not consume toxic chemicals, therefore the waste treatment can be simplified and the cost for the treatment is further reduced. Coch [59] suggested that the plating solution and the rinse water can be recycled many times without affecting the quality of the coatings formed, as long as the contamination level is well-monitored. Large fractions of previous-batch plating solution can still be used with the addition of fresh chemicals and coating metals. Compared to electroplating, mechanical plating shows potential cost saving in terms of chemicals usage (excluding labour or overhead), especially if a thicker coating is deposited [53], as shown in Fig. 4. Moreover, parts with holes (as small as $0.78 \mathrm{~mm}$ in diameter), which are usually hard to be electroplated to a desired thickness, can be successfully coated by mechanical plating [53].

On the other hand, mechanically plated coatings are highly porous $[60,61]$, and the coating thicknesses

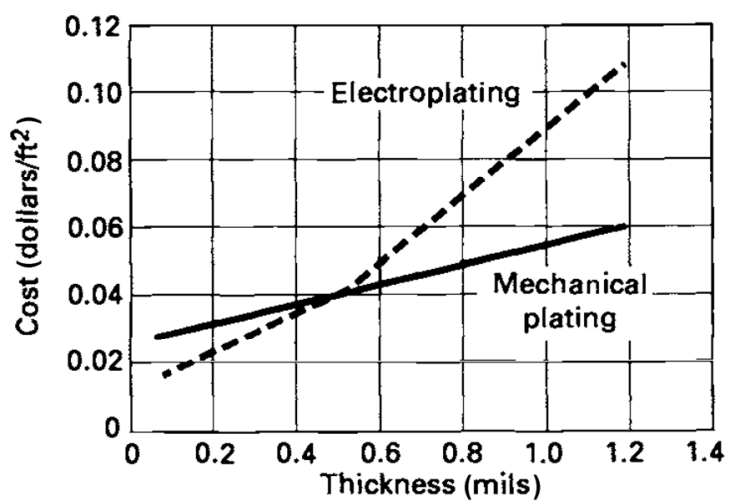

Fig. 4 Cost comparison of mechanical plating and electroplating in terms of chemicals used but not including labour or overhead. Reproduced with permission from Ref. [53], (C) ASM International, 1994. 
are usually not uniform [60], which may affect the corrosion protection. However, Wang et al. [60] reported that porosity in the coating did not substantially affect the corrosion resistance of mechanically plated $\mathrm{Zn}-\mathrm{Al}$ coating because the zinc that corroded initially played a role in sealing the pores and continued to sacrificially protect the steel susbtrate.

\subsection{Comparisons of advantages and disadvantages of different techniques}

The advantages and disadvantages of the above described techniques are summarized in Table 1.

\section{Microstructure of coatings formed by different techniques}

\subsection{Morphology and porosity}

Electroplated coatings are generally dense and compact. The morphology of the coatings is dependent on the process parameters. Solution composition, current density, agitation, solution acidity and temperature affect the deposition rate, and subsequently the properties of the coating such as uniformity, porosity and hardness [62]. The rate of deposition for pure zinc coating is generally small, approximately $5-8 \mu \mathrm{m} / \mathrm{h}$ $[63,64]$. Increasing current density will increase the deposition rate, however, if the rate is above a critical level for certain solution or temperature, a spongy and rough coating may be generated [62]. Different chemical composition formulae, namely rack plating formula and low hydrogen embrittling (LHE) formula, also affected the morphology on electroplated $\mathrm{Zn}-\mathrm{Ni}$ coatings [65]. The authors reported that LHE formula produced comparatively porous coatings, while rack plating formula formed much denser and smoother coatings.

Plating current density has great effect on the surface morphology of the coatings. The variation of the surface morphology of electroplated $\mathrm{Zn}-\mathrm{Ni}$ coatings using different current densities is shown in Fig. 5 [64]. Increasing the current density from $30 \mathrm{~mA} / \mathrm{cm}^{2}$ (Fig. 5(a-i)) to $48 \mathrm{~mA} / \mathrm{cm}^{2}$ (Fig. 5(a-ii)), very fine platelets of less than $1 \mu \mathrm{m}$ were noticed. In addition, some through-thickness microcracks in both $\mathrm{Zn}-\mathrm{Ni}$ coatings observed (Fig.5(b)), and the number of microcracks increased after post-plating heat treatment (200 ${ }^{\circ} \mathrm{C}$ for 24 hours) (Fig. 6). The application of a lower current density generated more pronounced microcracks (Fig. 6(b)).

In hot-dip galvanized coatings, zinc and iron are mutually bonded through diffusion of atoms, and thus forming the Fe- $\mathrm{Zn}$ alloys. The intermetallic phases (Fig. 7) in Fe-Zn alloys include gamma $(\Gamma)$, delta $(\delta)$, and zeta $(\zeta)$, while eta $(\eta)$ refers to the pure zinc at the outer layer. A very thin layer of $\Gamma$ phase is formed near to the steel substrate, while $\delta$ phase grows in a columnar-like morphology adjacent to the $\Gamma$ phase,

Table 1 Summary of the advantages and disadvantages for different coating deposition techniques.

\begin{tabular}{lllll}
\hline Deposition technique & & \multicolumn{1}{c}{ Advantages } & Disadvantages \\
\hline Electroplating & $\checkmark$ & Thin, smooth, dense, and adherent coating & $\times$ & High risk of hydrogen embrittlement \\
& $\checkmark$ & Capable of plating high performance alloy coatings & $\times$ Toxic plating solutions \\
& $\checkmark$ & Processing temperatures $<100{ }^{\circ} \mathrm{C}$ & $\times \quad$ More chemicals required for thicker coatings \\
& & & compared to mechanical plating \\
Hot-dip galvanizing & $\checkmark$ & Thick coating for longer corrosion protection & $\times$ & Risk of hydrogen embrittlement \\
& $\checkmark$ & Economical process & $\times$ & High processing temperatures \\
Ion vapour deposition & $\checkmark$ & Thin and adherent coatings & $\times$ & High equipment costs \\
& $\checkmark$ & Uniform coating thickness & $\times$ & Low lubricity coating \\
& $\checkmark$ & No risk of hydrogen embrittlement & $\times$ & Moderate processing temperatures \\
Mechanical plating & $\checkmark$ & Thin coatings & $\times$ & Highly porous and less adhesion coatings \\
& $\checkmark$ & No risk of hydrogen embrittlement & $\times$ Uneven coating thickness \\
& $\checkmark$ & Room temperature process & & \\
& $\checkmark$ & Environmentally-friendly plating solution &
\end{tabular}



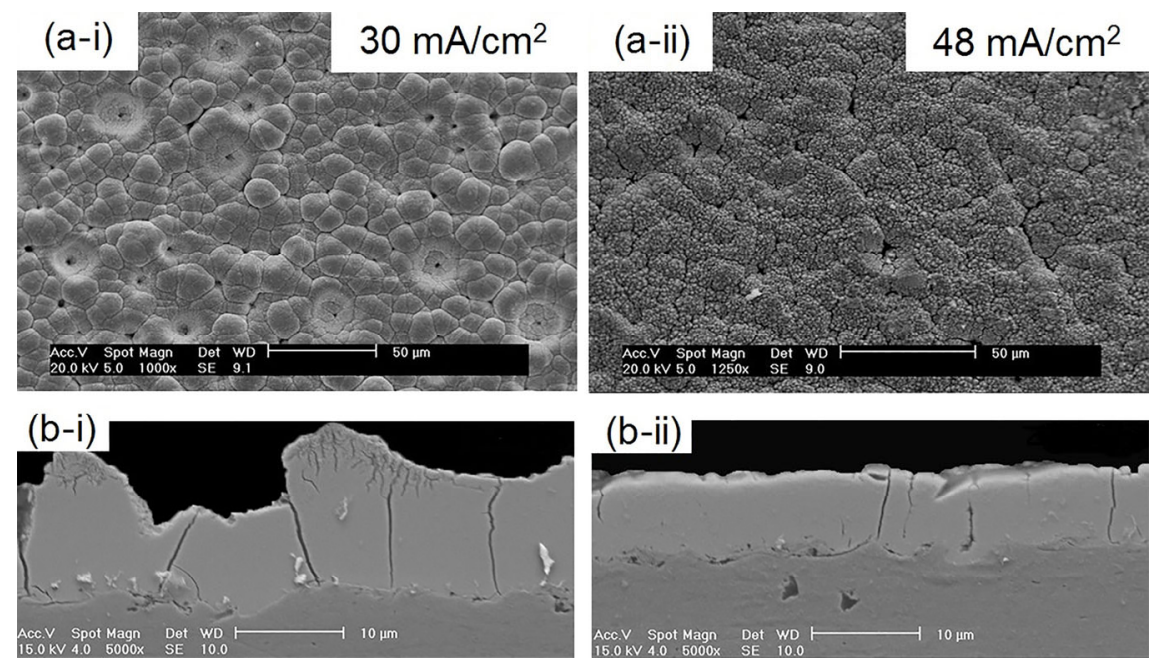

Fig. 5 (a) Surface morphology, and (b) cross-section images of trivalent chromate passivated $\mathrm{Zn}-\mathrm{Ni}$ coatings electroplated at current density of (i) $30 \mathrm{~mA} / \mathrm{cm}^{2}$ and (ii) $48 \mathrm{~mA} / \mathrm{cm}^{2}$. Reproduced with permission from Ref. [64], (c) Elsevier, 2013.
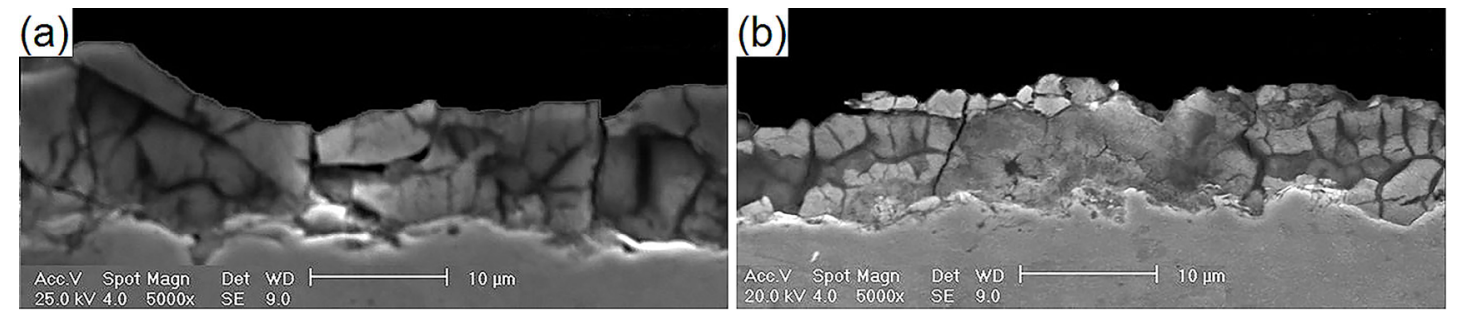

Fig. 6 Effect of post-plating heat treatment on $\mathrm{Zn}-\mathrm{Ni}$ coatings plated at current density of (a) $30 \mathrm{~mA} / \mathrm{cm}^{2}$ and (b) $48 \mathrm{~mA} / \mathrm{cm}^{2}$. Reproduced with permission from Ref. [64], C Elsevier, 2013.

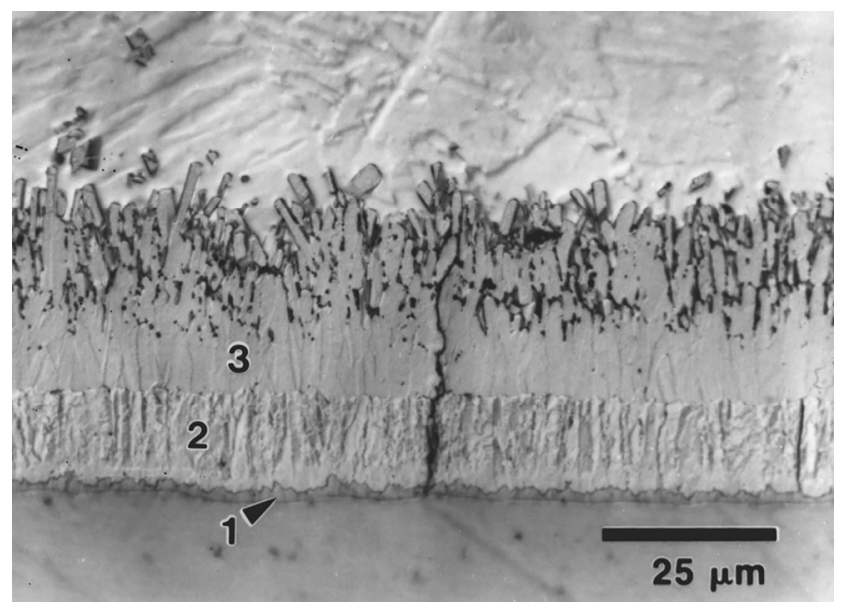

Fig. 7 Microstructure of $\mathrm{Zn}$ coating formed after $300 \mathrm{~s}$ immersion in a $450{ }^{\circ} \mathrm{C}$ pure $\mathrm{Zn}$ bath on an ultra-low-carbon (ULC) steel substrate. Phases formed are (1) gamma, $\Gamma$; (2) delta, $\delta$; and (3) zeta, $\zeta$. Reproduced with permission from Ref. [32], (c) Elsevier, 2000 .

and lastly, $\zeta$ phase appears to be the largest part of the coating in a very noticeable columnar needle-like morphology [32]. The formation of intermediate phases in hot-dip galvanized coating followed the sequence of $\zeta$ phase, $\delta$ phase and, after some incubation time of approximately $30 \mathrm{~s}, \Gamma$ phase [66]. The evolution of the intermetallic phases in hot-dip galvanized coating is substantially influenced by immersion time, at which the overall Fe- $\mathrm{Zn}$ alloy follows the growth kinetics of $t^{1 / 3}$ [66]. Small amount of $\mathrm{Al}$ is added to the molten zinc bath to form a barrier layer $\left(\mathrm{Fe}_{2} \mathrm{Al}_{5}\right)$ between Fe and Zn, leading to "outburst" formation or discontinuous growth of $\mathrm{Fe}-\mathrm{Zn}$ intermetallic phases $[67,68]$.

$\mathrm{Fe}-\mathrm{Zn}$ compounds, constituents, and hardness of the intermetallic phases formed in the hot-dip galvanized coating are listed in Table 2 [32]. The Fe- Zn intermetallic phases contributed greatly to the long-term corrosion resistant characteristics of galvanized steel in chloride containing environment [69].

Post-heat treatment on hot-dip galvanized coatings at temperatures of $530-600{ }^{\circ} \mathrm{C}$ is used to remove the pure $\mathrm{Zn}$ phase $(\eta)$ and produce galvanneal coatings composed of mostly ductile $\delta$ phase instead of brittle $\zeta$ and $\Gamma$ phases, since at this temperature range, the $\zeta$ 
Table $2 \mathrm{Fe}-\mathrm{Zn}$ phases, compounds, constituents, and hardness of the phases formed in $\mathrm{Fe}-\mathrm{Zn}$ system.

\begin{tabular}{cccc}
\hline Phases & Compound & $\begin{array}{c}\text { Fe-content } \\
(\text { wt. } \%)\end{array}$ & $\begin{array}{c}\text { Hardness } \\
\text { (VHN) }(25 \mathrm{mg})\end{array}$ \\
\hline$\eta-\mathrm{Zn}$ & $\mathrm{Zn}$ & 0.03 & 52 \\
$\zeta$ & $\mathrm{FeZn}_{13}$ & $5-6$ & 208 \\
$\delta$ & $\mathrm{FeZn}_{10}$ & $7-11.5$ & 358 \\
$\Gamma_{1}$ & $\mathrm{Fe}_{5} \mathrm{Zn}_{21}$ & $17-19.5$ & 505 \\
$\Gamma$ & $\mathrm{Fe}_{3} \mathrm{Zn}_{10}$ & $23.5-28$ & 326 \\
$\alpha-\mathrm{Fe}$ & $\mathrm{Fe}$ & $95-100$ & 104 \\
\hline
\end{tabular}

Source: Reproduced with permission from Ref. [32], (C) Elsevier, 2000 .

phase is eliminated, while the growth of $\Gamma$ phase is restrained [70-72].

Ion vapour deposition (IVD) coating is columnar-like in nature due to the nucleation process. The coating's structure formation depends on the process parameters such as ion bombardment of condensing atoms, surface roughness and temperature of the substrate, angle of incidence of vapour stream, deposition rate and gas pressure [45]. For example, high gas pressure with low discharge current density produces coarse columnar structure, while lower gas pressure with high current density tends to form dense and smooth structure.
Figure 8 illustrates the effects of the ion plating parameters on the coating structure formed [45]. Figure 9 illustrates the columnar-like structure in IVD-Al coating, and comparatively denser structure in non-aqueous electroplated $\mathrm{Al}$ coating.

As compared to other coatings, mechanically plated coatings are highly porous and rough. Figure 10 shows a higher porosity in a mechanically plated $\mathrm{Zn}-\mathrm{Sn}$ coating than electroplated $\mathrm{Al}$ coating which appeared highly dense. In addition, mechanically plated coatings exhibited a surface roughness of $2.32 \mu \mathrm{m}$, which was three times greater than that of electroplated aluminium coating $\left(R_{\mathrm{a}}=0.77 \mu \mathrm{m}\right)$ [61]. Wang et al. [60] studied the mechanically plated $\mathrm{Zn}-\mathrm{Al}$ coating, and observed that bonding formed at some of the interfaces between particles, as marked by the arrows in Fig. 11(a). After further investigating the fracture surface (Fig. 11(b)), the authors claimed that mechanical bonding was the predominant bonding mechanism between particles, and that there was not any alloy of compounds, a solid solution or a metal oxide formed in the coating. To reduce the gap between particles, $\mathrm{Lu}$ [73] used compounded $\mathrm{Zn}-\mathrm{Al}$ flake powders rather than granular powders. The flake powders were produced by ball milling the mixture of 325-screen mesh granular

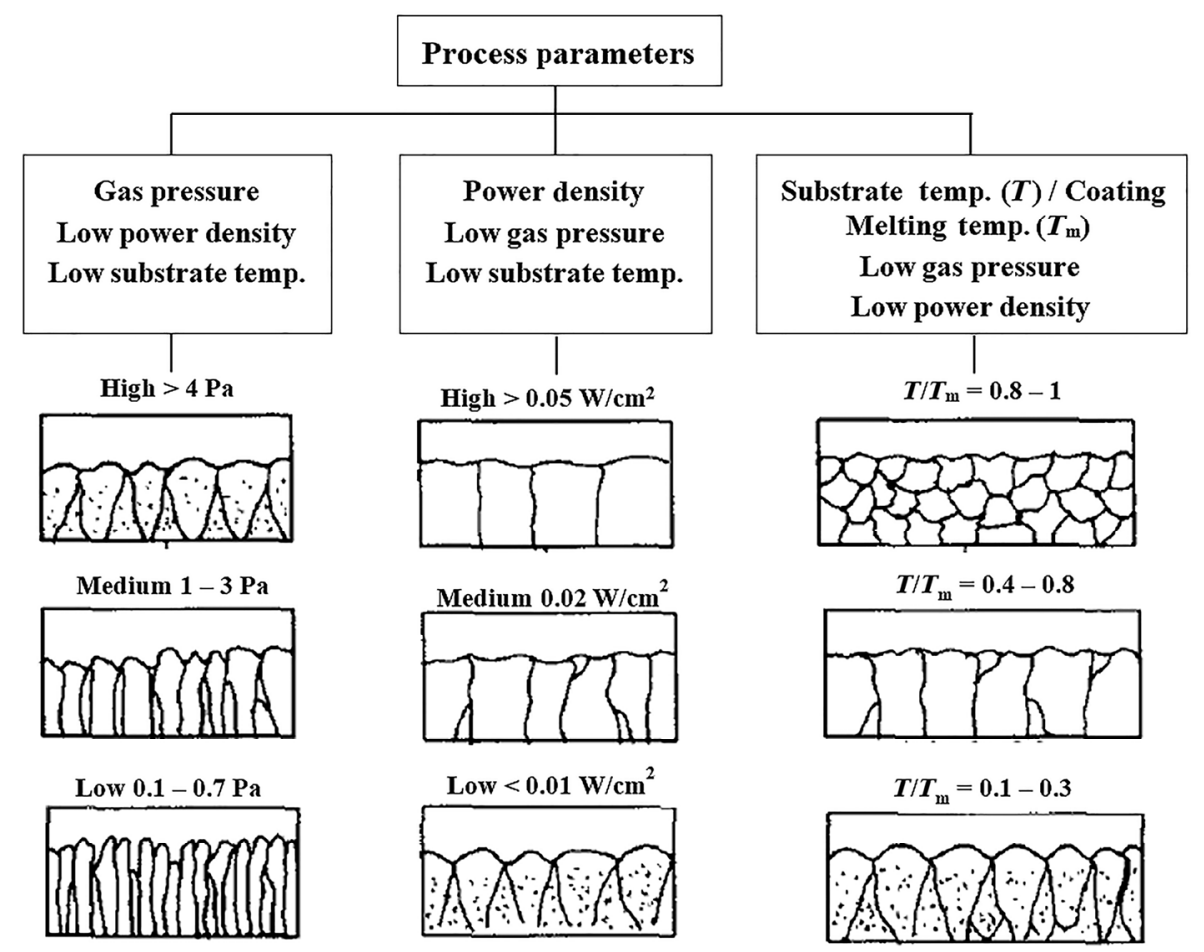

Fig. 8 Effects of ion plating process parameters on coating structure. Reproduced with permission from Ref. [45], (C) Elsevier, 1994. 

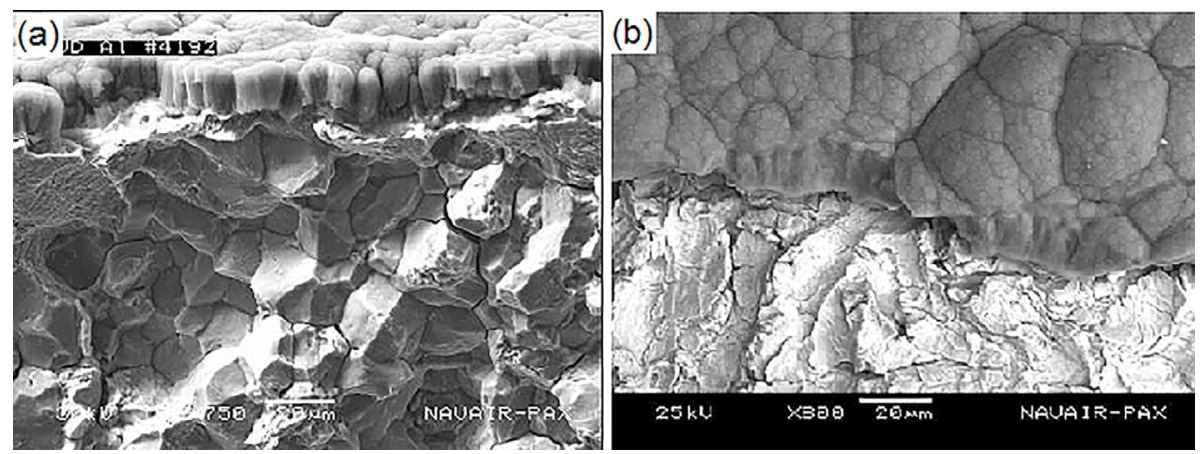

Fig. 9 The fracture image of (a) ion vapour deposited Al coating showing a columnar-like structure (top of the image), and (b) non-aqueous electroplated Al coating and exposed substrate. Reproduced with permission from Ref. [24], Licensed under Distribution Statement A, 2011.
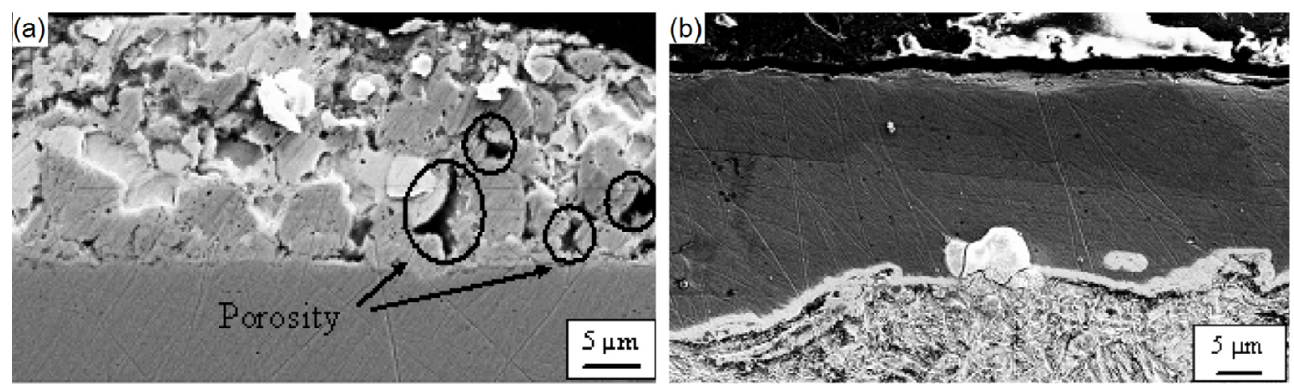

Fig. 10 Scanning electron micrographs of the cross section of (a) highly porous mechanically plated Zn-Sn, and (b) highly dense electroplated Al coatings on steel rivets' head. Reproduced with permission from Ref. [61], (C) Trans Tech Publications Ltd, 2012.
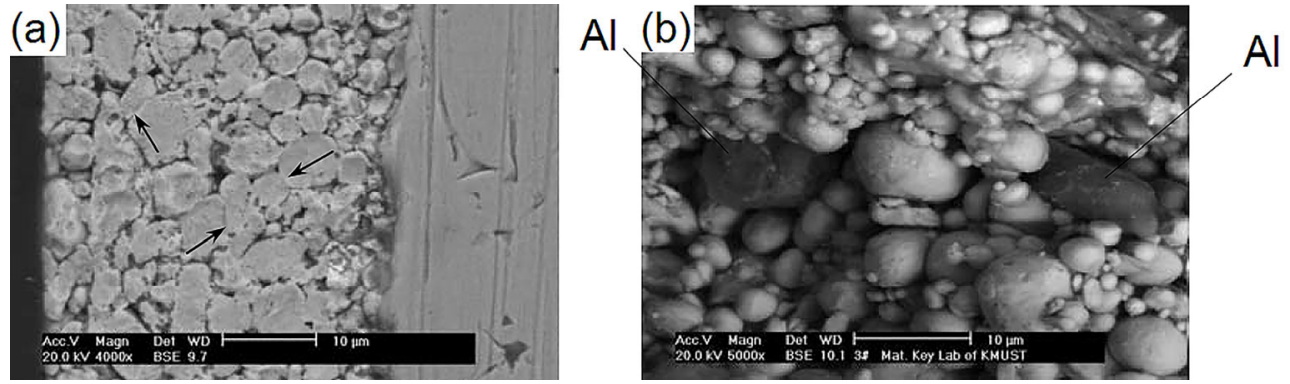

Fig. 11 Scanning electron micrograph of mechanically plated $\mathrm{Zn}-\mathrm{Al}$ coating from (a) cross section showing highly porous structure and the mark arrows show bonding at the interfaces between particles, and (b) fracture surface showing that the particles are mechanically bonded to each other. Reproduced with permission from Ref. [60], Licensed under CC BY, 2009.

$\mathrm{Zn}$ and $\mathrm{Al}$ powders. The mechanically plated $\mathrm{Zn}-\mathrm{Al}$ coating exhibited densely compacted structure compared to mechanically plated Zn coating, which formed using granular $\mathrm{Zn}$ powders. Heat treatment after mechanical plating was found to cause the formation of a Fe-Zn intermetallic layer between the Fe-substrate and the coating [74, 75]. Chung et al. [75] reported that the $\mathrm{Fe}-\mathrm{Zn}$ intermetallic layer formed in $\mathrm{Zn}-\mathrm{Sn}$ coating consisted of $\zeta-F e Z n_{13}, \delta-F e Z n_{7}$ and $\Gamma-F_{3} Z_{10}$ phases, while the outer coating was $S n$-rich though $\mathrm{Zn}$ and Sn particles were co-deposited during the mechanical plating process. The $\mathrm{Fe}-\mathrm{Zn}$ intermetallic layer was comparatively dense but the Sn-rich outer coating was highly porous.

In summary, electroplated coatings generally exhibit relatively dense and compact structure, while IVD coatings are columnar-like in nature. Hot-dip galvanised coatings compose of dense and compact Fe-Zn intermetallic phases, i.e., gamma $(\Gamma)$, delta $(\delta)$, and zeta $(\zeta)$. Mechanically plated coatings are highly porous and the particles are mechanically bonded to each other. Post-plating heat treatment on mechanically 
plated $\mathrm{Zn}$ and Zn-alloy coatings is able to form a dense and compact $\mathrm{Fe}-\mathrm{Zn}$ intermetallic layer.

\subsection{Adhesion and thickness uniformity}

Electroplated coatings usually adhere well to the substrate and have uniform thicknesses. However, in the studies of electroplated $\mathrm{Cd}, \mathrm{Zn}-\mathrm{Ni}, \mathrm{Zn}-\mathrm{Ni}_{2}$ and $\mathrm{Al}$ coatings on automotive fasteners, Brown et al. [76, 77] observed variations in coating thicknesses measured at different locations, and these variations could be due to the presence of voltage potential along the fasteners' length during the electroplating process. Though the thickness uniformity was not excellent, the authors claimed that the coatings were all well adhered to the substrates.

Hot-dip galvanized coatings are generally well adhered to the steel substrate due to the $\mathrm{Fe}-\mathrm{Zn}$ intermetallic phases formed. Gallego et al. [78] tested the adherence of galvanized coatings with different thicknesses (200-220 $\mu \mathrm{m}, 140-150 \mu \mathrm{m}$, and $\cong 100 \mu \mathrm{m}$ ) by using scratch test and acoustic emission wavelet analysis. The authors reported that there was no adherence failure at phase interfaces as the indenter had never touched the substrate and there was even no exposure of delta $(\delta)$ or gamma $(\Gamma)$ phase when the applied force gradually increased from 0 to $150 \mathrm{~N}$.

However, the adhesion of galvanized coating on high strength steel is greatly influenced by the alloying elements in the substrate [36], since the alloying elements tend to segregate to the steel surface and form oxide layer during annealing process. The oxide layer formed will then affect the wetting behaviour of molten zinc on the steel substrate during the galvanizing process, and consequently deteriorate the adhesion of the coating to the substrate. Song and Sloof [79] studied a series of alloying elements and concluded that $\mathrm{Mg}, \mathrm{Sn}$ and Bi caused adverse effect on zinc coating adhesion, while $\mathrm{P}, \mathrm{Ni}, \mathrm{Mo}, \mathrm{V}, \mathrm{Ti}$ and $\mathrm{Nb}$ were beneficial to the adhesion to the coating. In addition, $\mathrm{Al}, \mathrm{Mn}, \mathrm{Si}$ and $\mathrm{Cr}$ were able to enhance the coating adhesion if they were added into the zinc bath, but detrimental if they were present in the steel substrate. Shibli and Manu [80] reported that a layer of Ni-P applied before hot-dip galvanizing had attributed to better diffusion of zinc into steel substrate, and hence producing coating with good adhesion. No cracks or fissures were also observed during bending test up to $180^{\circ}$ on Ni-containing hot-dip Zn coating, which was produced by adding Ni-deposited $\mathrm{Zn}$ particles into the $\mathrm{Zn}$ bath [81]. Song et al. [82] conducted $5 \mathrm{kN}$ tensile test on galvanized dual phase steel containing 1.508 wt.\% Mn, and observed occurrence of fracture after $4 \%$ tensile strain (Fig. 12(a)). Partial delamination was then observed after 13\% tensile strain (Fig. 12(b)). The authors reported that cracks initiated at the zinc grain boundaries, and then propagated along the zinc layer/inhibition layer and $\zeta-\mathrm{FeZn}_{13}$ particle/inhibition layer interfaces. The authors then predicted the work of adhesion at various interfaces (Table 3) and reported that the interface of inhibition layer/steel substrate was the strongest, while other interfaces were considerably
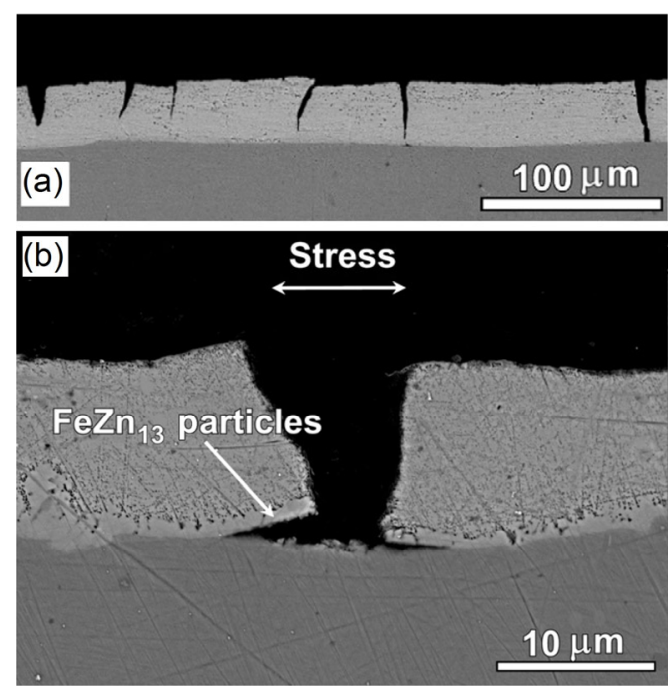

Fig. 12 Scanning electron micrographs of galvanized zinc coating on dual phase steel showing (a) fracture after $4 \%$ tensile strain, and (b) partial delamination after 13\% tensile strain. Reproduced with permission from Ref. [82], (c) Elsevier, 2012.

Table 3 Predicted work of adhesion at various interfaces in galvanized dual phase steel.

\begin{tabular}{cc}
\hline Interface & Work of adhesion $\left(\mathrm{J} / \mathrm{m}^{2}\right)$ \\
\hline$\eta-\mathrm{Zn} / \mathrm{Fe}_{2} \mathrm{Al}_{5-x} \mathrm{Zn}_{x}$ & 2.03 \\
$\zeta-\mathrm{FeZn}_{13} / \eta-\mathrm{Zn}$ & 1.66 \\
$\zeta-\mathrm{FeZn}_{13} / \mathrm{Fe}_{2} \mathrm{Al}_{5-x} \mathrm{Zn}_{x}$ & 2.12 \\
$\mathrm{Fe}_{2} \mathrm{Al}_{5-x} \mathrm{Zn}_{x} /$ steel & 3.54 \\
$\mathrm{Fe}_{2} \mathrm{Al}_{5-x} \mathrm{Zn}_{x} / \mathrm{MnO}$ & 2.79 \\
$\eta-\mathrm{Zn} / \mathrm{MnO}$ & 2.17 \\
$\mathrm{Steel} / \mathrm{MnO}$ & 3.34
\end{tabular}

Source: Reproduced with permission from Ref. [82], (C) Elsevier, 2012. 
weak at which delamination was preferentially to occur. Blumenau et al. [38] suggested an additional pre-oxidation treatment before annealing the highmanganese (23 wt.\%) steel was able to form a Fe-Mn mixed oxide that can improve the wetting behaviour of $\mathrm{Zn}$ during hot-dip galvanizing. Arndt et al. [39] also reported that $\mathrm{Zn}$ layer was able to adhere directly onto the Fe-Mn oxide layer as compared to the nonpre-oxidized sample. However, the authors did not perform adhesion test on the Zn coatings formed.

Ion vapour deposited (IVD) aluminium coatings also exhibit good adhesion and thickness uniformity $[83,84]$. The thickness uniformity of IVD coatings depends on the orientation of the part in the chamber and thus not all coated areas are equivalent [24]. Ahmed [84] reported that the IVD-Al coating thickness ratio between the crest and root of the thread was about 3:2 and the ratio between the shank and crest was about 1:1. Holmes and Bridger [50] reported that the adhesion of IVD coating impaired when the coating was applied in a thick range from 63.5 to $73 \mu \mathrm{m}$ due to the stress built up. Brown and Berman [24] conducted a bend adhesion test, in which the specimen was bent back and forth through $180^{\circ}$ until the coating and/or substrate ruptured, on thin coatings (approximately 12-23 $\mu \mathrm{m}$ ), and reported that IVD-Al coating exhibited substantial flaking/peeling before the substrate failed. On the other hand, non-aqueous electroplated Al coating showed very minor peeling after the test. Remnant of $\mathrm{Al}$ from the fractured IVD coating was observed on 4130 steel substrate (Fig. 13(a)), but when the non-aqueous electroplated $\mathrm{Al}$ coating peeled off the iron particles were also being pulled from the steel substrate (Fig. 13(b)).

The thickness of mechanically plated coating is comparatively uneven. Wang et al. [60] reported that the coating thicknesses of mechanically plated $\mathrm{Zn}-\mathrm{Al}$ coating on steel washers varied from 2 to $15 \mu \mathrm{m}$. From the adhesion point of view, Esfahani et al. [61] observed that part of the mechanically plated $\mathrm{Zn}-\mathrm{Sn}$ coating at the edge of the rivet head was missing (Fig. 14) after the laser assisted self-piercing riveting (SPR) joining process. The authors suggested that the coating might have been removed during the piercing process, or the coating had not even adhered well to the surface before the joining process. Chrysanthou [85] stated that damage of the mechanically plated $\mathrm{Zn}$-based
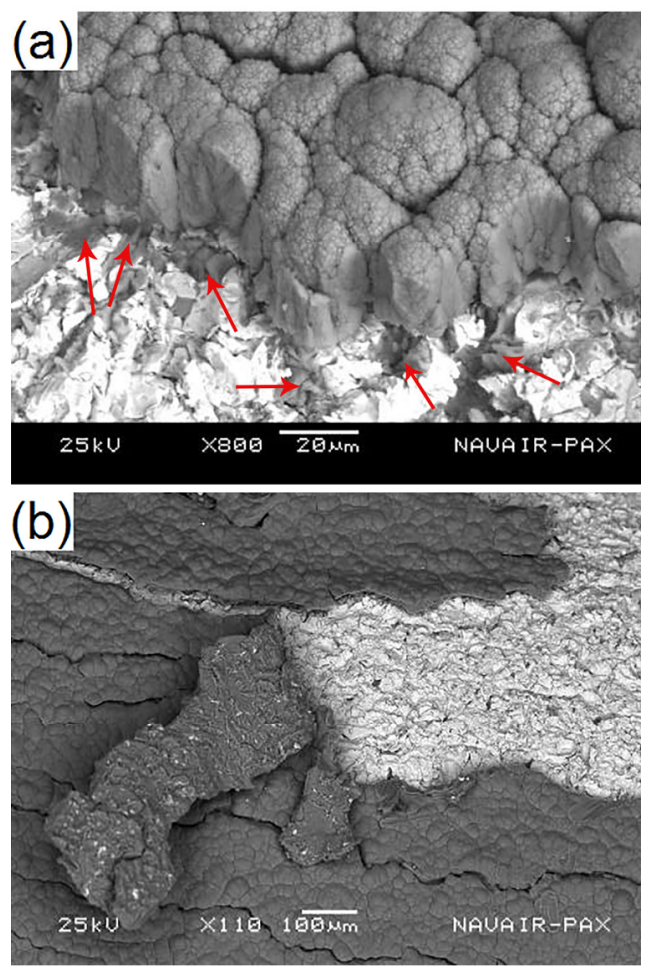

Fig. 13 Images after bend adhesion test. (a) Oblique view of fractured IVD-Al coating and exposed substrate, showing remnant of $\mathrm{Al}$ on 4130 steel substrate (arrows). (b) Non-aqueous electroplated Al coating peeling away from 4130 steel substrate at which the bright flecks at the underside of the coatings are the Fe particles that were pulled from the substrate. Reproduced with permission from Ref. [24], Licensed under Distribution Statement A, 2011.

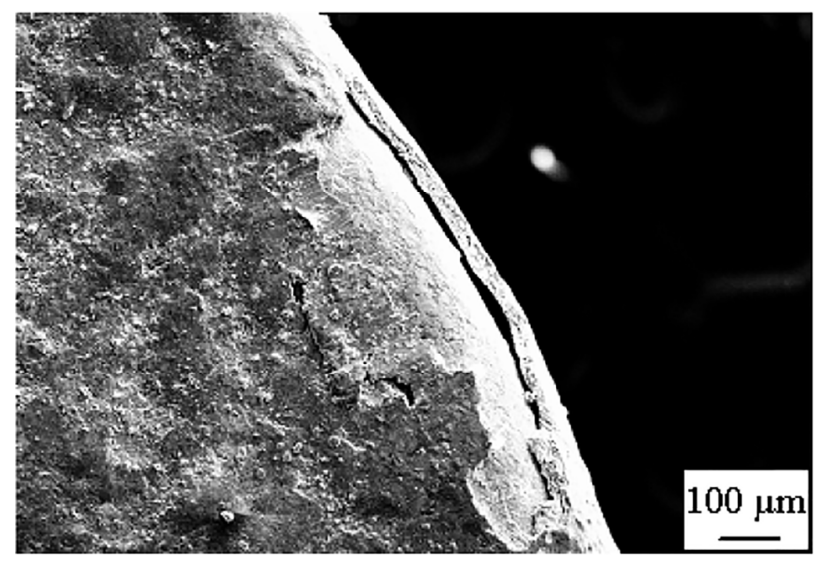

Fig. 14 Scanning electron micrograph image of the edge of $\mathrm{Zn}-\mathrm{Sn}$ rivet's head showing part of the coating was missing. Reproduced with permission from Ref. [61], (C) Trans Tech Publications Ltd, 2012.

coating is common during the piercing and locking stage of the SPR process. In this case, the underlying steel in the rivet will be exposed to the environment and corrosion will be initiated even at the early stage 
of the salt-spray test.

Wang et al. [86] studied the bonding between the steel substrate and mechanically plated Zn coatings, and reported that it was principally physical bonding at which a distinct interface was observed (Fig. 15). In their study, tin was mainly concentrated at the interface layer between the substrate and coating, acting as a bonding medium. The authors also reported that no alloy phases such as Zn-Sn, Zn-Fe and Fe-Sn were detected at the interface and no $\mathrm{Zn}-\mathrm{Fe}$ diffusion occurred during the mechanical plating process.

Ding [87] applied a base coating after copper flash in mechanical plating by using tin (II) sulphate solution and showed that tin played a role in bonding the $\mathrm{Zn}$ coating deposit. The author also found that $\mathrm{Sn}^{2+}$ was deoxidized, and initially formed an antenna-like structure that broke when it grew to a certain extent on the surface of $\mathrm{Zn}$ particles. The broken tin antenna then joined into flakes, and filled in the gaps among the $\mathrm{Zn}$ particles, and eventually connected the adjacent $\mathrm{Zn}$ particles to form the coating. The author also reported that the coating formation did not involve any crystallization.

In short, the morphology, microstructure, adhesion and thickness uniformity of coatings are greatly influenced by the process parameters and subsequently affecting the performances of the coatings.

\section{Performances of coatings formed by different techniques}

\subsection{Corrosion resistance}

Zinc and cadmium are two most common metals deposited on steel fasteners to sacrificially protect the fasteners from corrosion since they are more anodic in both electromotive force (EMF) and galvanic series as compared to steel [88]. The anodic coating provides excellent protection to the steel even there is a void in the coating, as shown schematically in Fig. 16. However, due to the toxicity issue with cadmium coating, its usage has been banned since 1980s [89].

Zinc coatings are particularly useful in atmospheric environment including rural, urban, industrial and marine atmospheres [25]. The service life of electroplated and galvanized zinc coatings was reported directly proportional to the coating thicknesses, as seen

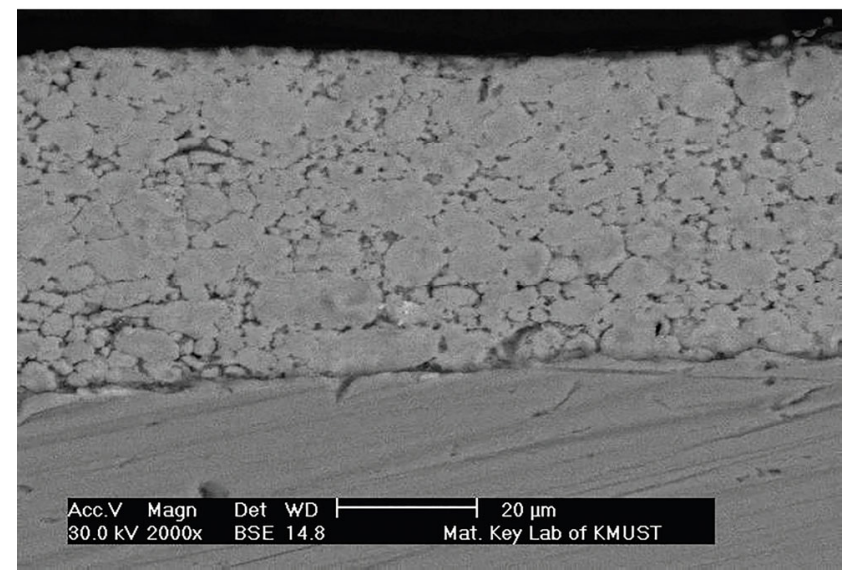

Fig. 15 Scanning electron micrograph image of the distinct coating/substrate interface observed. Reproduced with permission from Ref. [86], (C) Elsevier, 2013.

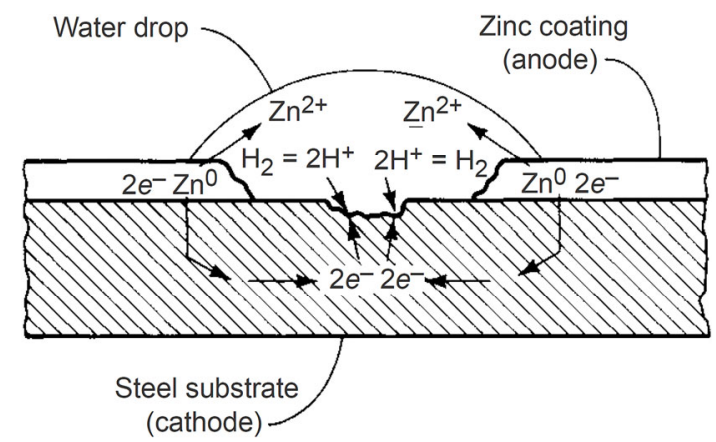

Fig. 16 Sacrificial protection of the steel substrate at a void in zinc coating. Reproduced with permission from Ref. [88], C ASM International, 2000.

in Fig. 17 [90]. Table 4 [90] compares the corrosion rates of zinc with other metals at industrial, marine and rural environment. Cadmium has higher corrosion rates than $\mathrm{Zn}$ at all atmospheres, while aluminium is the only metal that performs better than $\mathrm{Zn}$ at these atmospheres. Tin and magnesium are more corrosion resistant than $\mathrm{Zn}$ at industrial environment, but less corrosion resistant than $\mathrm{Zn}$ at marine and rural environment.

In order to enhance the service life of the fasteners as well as for the best economical consideration, sacrificial coatings are normally finished with conversion coating such as hexavalent chromium, trivalent chromium and non-chromium passivation [17]. However, due to the adverse effect of hexavalent chromium, its usage has been phased out, particularly in US and Europe. As a result, additional sealant or top coat may be applied to the hexavalent chromiumfree passivated surface to achieve the same level of 


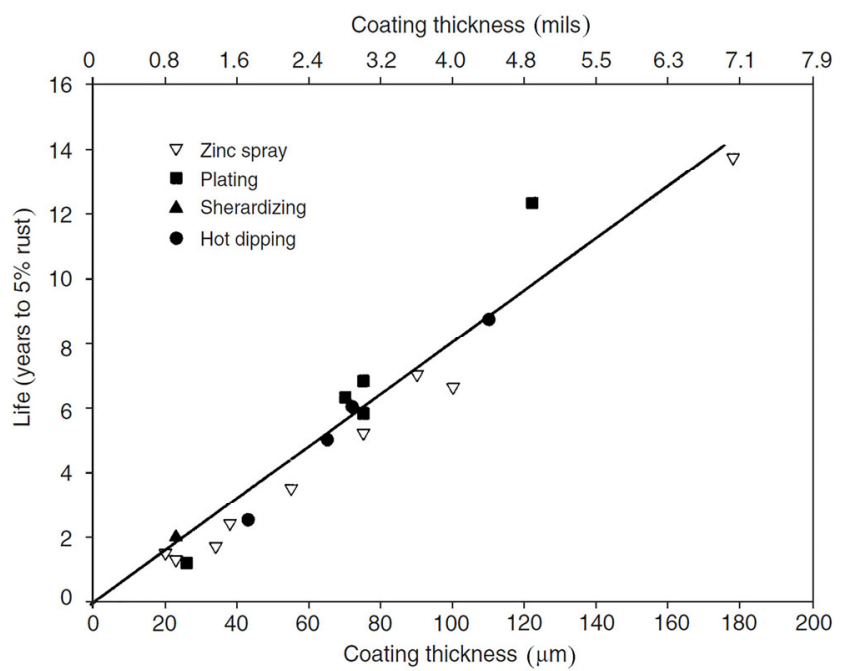

Fig. 17 Effect of zinc coating thicknesses and coating methods on coating life in industrial atmospheres. Reproduced with permission from Ref. [90], (C) ASM International, 2005.

Table 4 Comparison of corrosion rates* of zinc and other common commercial metals.

\begin{tabular}{cccc}
\hline Metal & Industrial & Marine & Rural \\
\hline Zinc & 1 & 1 & 1 \\
Cadmium & 2 & 2 & 2.4 \\
Tin & 0.23 & 1.6 & 1.9 \\
Aluminium & 0.13 & 0.3 & 0.09 \\
Copper & 2.4 & 0.72 & 0.39 \\
Nickel & $\ldots$ & 0.6 & 1.1 \\
Magnesium & 0.31 & 1.8 & 1.9 \\
Iron & 30 & 50 & 15 \\
\hline
\end{tabular}

*Note: Corrosion rate is relative to zinc, which is taken as 1 . Source: Reproduced with permission from Ref. [90], (C) ASM International, 2005.

corrosion resistance that was provided by hexavalent chromium [91]. Instead of applying chromate conversion coating, McCune et al. [51] applied an inorganic electrophoretic coating, which is a ceramic-like highly insulating layer, and a final layer of a polymeric sealant on IVD-Al and non-aqueous electroplated $\mathrm{Al}$ coatings. The authors reported that the corrosion resistant performance of these coatings on self-piercing rivets had greatly improved.

The corrosion protection of zinc is not only affected by the coating thickness, but is also dependent on the composition and microstructure of the coating [92]. In order to enhance the corrosion resistance of zinc coatings, alloying with other elements in electroplated
Zn coatings has been studied extensively [93-96], for instance, Zn-Fe [97, 98], Zn-Ni [64, 65, 99, 101], Zn-Co [102, 103] and Sn-Zn [104-106]. These zinc-alloy coatings were reported exhibiting better corrosion resistance than pure zinc coating because they still maintain the similar sacrificial property, but corrode in a slower rate than zinc when exposed to a corrosive environment [15]. Table 5 [15] shows the corrosion rates of some electroplated zinc alloy coatings (with yellow chromate) in neutral salt spray test. Ramanauskas et al. [95] reported that Fe did not contribute much to the corrosion resistance of electroplated $\mathrm{Zn}-\mathrm{Fe}(0.4 \%)$ coating as compared to the contribution of $\mathrm{Ni}$ and $\mathrm{Co}$ in the electroplated $\mathrm{Zn}-\mathrm{Ni}(12 \%)$ and $\mathrm{Zn}-\mathrm{Co}(0.6 \%)$ coatings. $\mathrm{Zn}-\mathrm{Ni}$ coatings exhibited the best corrosion resistance among the studied coatings due to the presence of dominant basal planes with a higher packing density. Unique chemical composition and phase composition also contributed to the outstanding corrosion resistance of $\mathrm{Zn}-\mathrm{Ni}$ coatings [101]. For example, $\mathrm{Zn}-\mathrm{Ni}$ coatings with 19 at. $\% \mathrm{Ni}$ and $\gamma-\mathrm{Ni}_{5} \mathrm{Zn}_{21}$ intermetallic phase showed the best corrosion resistant characteristics among the studied $\mathrm{Zn}-\mathrm{Ni}$ coatings [101].

Lodhi et al. [107, 108] investigated higher Co-content in $\mathrm{Zn}-\mathrm{Co}$ (up to $32 \mathrm{wt}$.\%) and Zn-Co-Fe (up to $40 \mathrm{wt} . \%$ $\mathrm{Co}$ and 1 wt.\% Fe) coatings electroplated on high strength steel, a commonly used material for fasteners. The authors reported that $\mathrm{Zn}-\mathrm{Co}-\mathrm{Fe}$ coatings with Co content more than $30 \mathrm{wt} . \%$ were comparable to $\mathrm{Cd}$ coatings and exhibited superior corrosion resistance than pure $\mathrm{Zn}$ coatings and $\mathrm{Zn}-\mathrm{Co}-\mathrm{Fe}$ coatings with low Co-content $(<7 \mathrm{wt}$.\%). In addition, dezincification occurred on $\mathrm{Zn}-\mathrm{Co}-\mathrm{Fe}$ coatings containing 34-40 wt.\% $\mathrm{Co}$ after long hours of immersion in $3.5 \% \mathrm{NaCl}$

Table 5 Hours to red rust in neutral salt spray test on electroplated zinc alloy coatings.

\begin{tabular}{cc}
\hline Coating* & Hours to red rust \\
\hline $\mathrm{Zn}$ & $200-250$ \\
$\mathrm{Zn}-\mathrm{Fe}(1 \% \mathrm{Fe})$ & 350 \\
$\mathrm{Zn}-\mathrm{Co}(0.8 \% \mathrm{Co})$ & 500 \\
$\mathrm{Zn}-\mathrm{Ni}(8 \% \mathrm{Ni})$ & 1000 \\
$\mathrm{Sn}-\mathrm{Zn}(70 \% \mathrm{Sn})$ & 1000
\end{tabular}

* Coating thickness is $8 \mu \mathrm{m}$ with iridescent yellow chromate post treatment.

Source: Reproduced with permission from Ref. [15], (C) ASM International, 1994. 
solution, and resulted in Co-rich coatings. Consequently, these coatings become nobler than steel, and thus lose their sacrificial protection property.

Fasteners with electroplated $\mathrm{Sn}-\mathrm{Zn}$ coatings with 50-90 wt.\% Sn exhibited improved galvanic corrosion resistance and coating stability at higher temperatures [105]. Sn-Zn (80-20 wt.\%) coatings electroplated from a non-cyanide alkaline bath displayed better corrosion resistant performance than electroplated $\mathrm{Cd}$ and Zn-Ni (78-12 wt.\%) coatings [106]. Their using X-ray fluorescence spectrometry (XRF) results showed that it was selective corrosion, at which the zinc had been completely dissolved during the corrosion process, leaving all tin left after the corrosion test.

To further enhance the corrosion resistant performance on fasteners in severe corrosive environments, multi-layer coatings in the sequence of Ni-based alloy, $\mathrm{Zn}$-based alloy, $\mathrm{Zn}$, followed by plating of $\mathrm{Cu}, \mathrm{Ni}$ and $\mathrm{Cr}$ were developed. The reported corrosion protection of such multi-layer coatings were comparable to those coatings consisting of cadmium as an intermediate layer [109].

Hot-dip galvanized coatings also provide excellent corrosion protection at rural environment and fairly good protection at heavy industrial atmosphere (Fig. 18) [27, 90]. Yadav et al. [69] reported that the long-term corrosion resistance of hot-dip galvanized coating in chloride containing environments was mainly attributed by the Fe-Zn alloy, which formed due to the diffusion of $\mathrm{Zn}$ and Fe. The corrosion rate of the alloy layer was lower than that of the zinc coating, which is equivalent to the lowest corrosion rate of galvanized steel.

Though zinc coating thickness is the main factor that affects the corrosion resistance of hot-dipped galvanized coatings [27], with addition of alloying elements the corrosion resistant performance improved significantly [90]. Galfan (5 wt.\% Al) and Galvalume (55 wt.\% Al) were reported two times and two to four times, respectively, more corrosion resistant than galvanized coatings. Ni-containing hot-dip Zn coating exhibited enhanced corrosion resistance and the improvement increased with higher nickel concentration [81]. Ni facilitated the diffusion of $\mathrm{Zn}$ into the steel substrate to form more compact inner alloy layer that gives lower dissolution rate of zinc. Galvanised $\mathrm{Zn}-\mathrm{Sn}$ alloy coatings also displayed outstanding corrosion resistance when compared to their pure

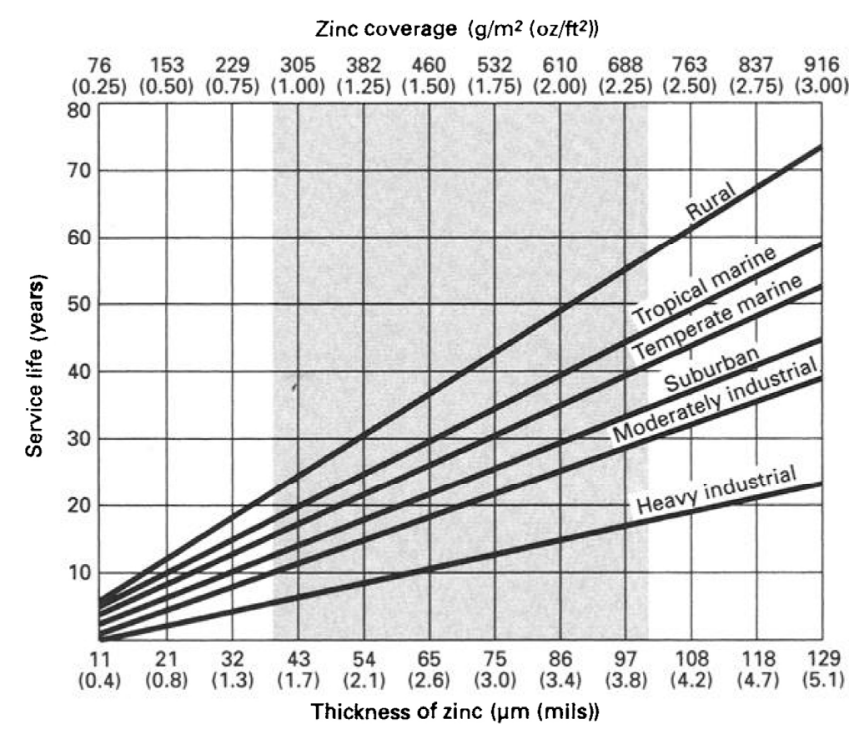

Fig. 18 Service life (time to 5\% rusting of steel surface) at different atmospheres as a function of the galvanized coating thickness. Reproduced with permission from Ref. [27], (C) ASM International, 1994.

zinc counterparts, with a five-time improvement from 300 to 1,500 hours in salt spray test [110]. To further improve the corrosion resistance of fastener's coatings, a combined deposition techniques have been used for preparing a series of coatings. Eriksson et al. [111] applied the first layer with hot-dip galvanized coating, followed by the second layer of zinc-electroplated coating on fasteners, and reported a greatly improved corrosion resistant performance.

It has been demonstrated that the service environment of the coating plays a key role in its corrosion resistance. The actual in-service environment for commercial and military industrial sites is mostly polluted with sulphur dioxide $\left(\mathrm{SO}_{2}\right)$ emitted from smokestacks. When sulphur dioxide combines with water, it forms sulphuric acid, and may eventually create an extremely corrosive environment. Holmes et al. [41] reported that compared to ion vapour deposited (IVD) aluminium coatings, electroplated Cd coatings with equal thickness exhibited better corrosion protection in neutral salt fog environment. However, IVD-Al coated fasteners performed better than those electroplated $\mathrm{Cd}$ coated counterparts in acidic salt fog environment and most outdoor environment. This is consistent with Ahmed [112] that IVD-Al coated fasteners showed superior corrosion resistant performance than electroplated $\mathrm{Cd}$ fasteners after 168 hours of $\mathrm{SO}_{2}$ salt spray exposure. 
Brown and Berman [24] conducted cyclic $\mathrm{SO}_{2}$ salt spray exposure test (both unscribed and scribed) on electroplated $\mathrm{Cd}$, low hydrogen embrittling (LHE) electroplated $\mathrm{Zn}-\mathrm{Ni}$, IVD-Al and non-aqueous electroplated $\mathrm{Al}$ coatings, and reported that electroplated $\mathrm{Cd}$ coating performed the worst, followed by LHE $\mathrm{Zn}-\mathrm{Ni}$ coating. Electroplated Cd coating exhibited red rust after 96-hour exposure, while IVD-Al coating showed red rust prior to 504-hour inspection, and non-aqueous electroplated-Al coating performed the best after 668 hours. The study also proved that deleterious corrosion occurred if there was a scratch on the IVD-Al coating. For the scribed coated panel, IVD-Al exhibited red rust after 336-hour exposure in cyclic $\mathrm{SO}_{2}$ salt spray. In order to inhibit deteriorating corrosion effect, Teer and Zeid [113] suggested adding alloying elements such as zinc into IVD Al coating since IVD Al-Zn coating had sacrificially protected the uncoated steel surface as compared to pure Al coating.

In addition to depositing pure $\mathrm{Zn}$ or $\mathrm{Cd}$ coatings, mechanical plating is also able to deposit combination coatings [55, 114] such as Zn-Al [115], Zn-Al-Sn [116], Zn-Mn [117] and Zn-Sn [118]. Similar to electroplated Zn-alloy coatings, the corrosion resistance of mechanically plated Zn-alloy coatings, such as $\mathrm{Zn}-\mathrm{Sn}$ and $\mathrm{Zn}-\mathrm{Al}$ coatings, was reported to be much better than mechanically plated pure zinc coatings in salt spray corrosion test, as shown in Table 6 . The corrosion resistance of mechanically plated $\mathrm{Zn}$ and Zn-alloy coatings is also thickness-dependent. Heat treatment after mechanical plating process had remarkably enhanced the corrosion resistance of $\mathrm{Zn}$ and $\mathrm{Zn}-\mathrm{Sn}$ coatings [74]. Chung et al. [75] reported that the improved corrosion resistance of fasteners with heat-treated $\mathrm{Zn}$-Sn coating was attributed to the $\mathrm{Fe}-\mathrm{Zn}$ intermetallic layer formed after heat treatment. The dissolution rate of $\mathrm{Zn}$ from $\mathrm{Fe}-\mathrm{Zn}$ intermetallic layer was slower than that from pure zinc due to its more positive potential compared to pure zinc.

McCune et al. [51] compared the galvanic coupling current at steady state between various coated selfpiercing steel rivets and coupons of magnesium alloys, and reported that without chromate conversion coating or any further finishing, mechanically plated Zn-Sn coatings had the lowest corrosion rate, followed by the non-aqueous electroplated aluminium, and lastly IVD aluminium coatings.
Table 6 Hours to red rust in 5\% neutral salt spray test (ASTM B-117) of mechanically plated steel washers.

\begin{tabular}{cccc}
\hline Coating & Thickness $(\mu \mathrm{m})$ & $\begin{array}{c}\text { Hours to } \\
\text { red rust }\end{array}$ & Ref. \\
\hline $8^{*}$ & 120 & {$[55,114]$} \\
$12^{*}$ & 140 & {$[55,114]$} \\
$20^{*}$ & 180 & {$[55,114]$} \\
20 & 212 & {$[60]$} \\
$\mathrm{Zn}$ & 30 & 296 & {$[60]$} \\
40 & 379 & {$[60]$} \\
$75^{* *}$ & $>600$ & {$[55,114]$} \\
Zn-Sn* & $3 \mu \mathrm{m} \mathrm{Sn}+7 \mu \mathrm{m} \mathrm{Zn}$ & $>350$ & {$[55]$} \\
& $4.5 \mu \mathrm{m}$ Sn $+10.5 \mu \mathrm{m}$ Zn & $>450$ & {$[55]$} \\
20 & 260 & {$[60]$} \\
Zn-Al & 30 & 420 & {$[60]$} \\
& 40 & 490 & {$[60]$} \\
\hline * Coatings are finished with yellow chromate post treatment. \\
* Normally referred to mechanical galvanizing and tested without \\
chromate passivation.
\end{tabular}

Besides the contribution from alloying elements to enhancing the corrosion resistance, the morphology of the coating also affects its performance. Dense, uniform and smooth coatings are generally desired for better protection as rough surface tends to cause localized corrosion [119]. Chandak et al. [119] compared fastener coatings produced by electroplating and hot-dipping, and reported that smooth textures of electroplated coatings exhibited consistent corrosion resistant performance while hot-dipped coatings, which have comparatively rough surfaces, did not perform anti-corrosion property consistently. Lu [73] found that mechanically plated $\mathrm{Zn}-\mathrm{Al}$ coatings formed using $\mathrm{Zn}-\mathrm{Al}$ compounded flake powders exhibited greatly improved corrosion resistance. The author believed that the densely compacted structure and the stacked-up layers had acted as the shield and prevented pitting and further corrosion phenomenon.

Discontinuous coating was reported causing the diffusion of the corrosion environment, and hence leading to more active corrosion [64]. Sriraman et al. [64] found that the higher corrosion current $\left(I_{\text {corr }}\right)$ detected in low hydrogen embrittling (LHE) electroplated-Cd coating as compared to electroplated $\mathrm{Cd}-\mathrm{Ti}$ coating was due to the effect of the discontinuities of the coating. In their study, the authors also found that electroplated $\mathrm{Zn}-\mathrm{Ni}$ coating with 
micropores (Fig. 5(b-i)) caused higher diffusion of the corrosive environment and subsequently higher rate of dezincification. However, the corrosion products formed through dezincification in fact provided an additional protection to the underlying coating. As a result, $\mathrm{Zn}-\mathrm{Ni}$ coatings were reported to show superior corrosion resistance as compared to $\mathrm{Zn}, \mathrm{Cd}$ and $\mathrm{Cd}-\mathrm{Ti}$ coatings. McCune et al. [51] also found that the porous characteristics of IVD-Al coating caused greater corrosion on the galvanic coupling between rivet and magnesium plate as compared to non-aqueous electroplated $\mathrm{Al}$ coating, which had the same insulating layer and a top sealant. Wang et al. [60] explained that porosity in the coating did not significantly affect the corrosion resistance of mechanically plated $\mathrm{Zn}-\mathrm{Al}$ coating because the zinc that corroded initially had played a role in sealing the pores and continued to sacrificially protect the steel susbtrate.

In summary, $\mathrm{Zn}$ is the most common metal deposited on fasteners mainly due to its sacrificial characteristics in protecting steels. Alloying with other elements such as $\mathrm{Ni}, \mathrm{Co}, \mathrm{Fe}, \mathrm{Sn}$ and $\mathrm{Al}$ effectively increases the corrosion resistance of $\mathrm{Zn}$ coating. Corrosion resistant performance of Zn-based coatings depends on not only the coating thicknesses, but also the morphology and microstructure of the coatings. Electroplated coatings perform better than those deposited by other methods mainly due to their denser and more compact structures formed. A final layer of conversion coating or topcoat is normally applied to the fastener coating to achieve longer corrosion protection.

\subsection{Frictional characteristics}

The performance of coatings on fasteners is obviously critical, not only in service to protect the fastener material and prevent galvanic corrosion when such advanced materials are used, but also during assembly when the adherence and frictional properties of coatings can impact the integrity of joints and their subsequent behaviour in service. Frictional characteristics of coatings also affect the energy consumption and carbon dioxide emissions during assembly of the joints [120].

Cadmium coating is applied to fasteners due to its outstanding corrosion resistance and excellent lubricity characteristic [91, 121]. However, cadmium has been strictly banned since 1980s due to its toxicity, and therefore, studies on its replacement on fasteners have been carried out extensively since then [91], such as electroplated $\mathrm{Zi}-\mathrm{Ni}, \mathrm{Zi}-\mathrm{Ni}_{2}$, and non-aqueous electroplated-Al [24, 76, 77, 121]. The authors demonstrated that the performances of these three coatings were quite similar to those provided by $\mathrm{Cd}$, but no individual coating offered the same broad range of properties as Cd plating did. Brown et al. [76] reported that with the assistance of secondary lubricant, the torque-tension relationships of $\mathrm{Zn}-\mathrm{Ni}, \mathrm{Zn}-\mathrm{Ni}_{2}$ and $\mathrm{Al}$ coatings were similar to the performance of $\mathrm{Cd}$ coating. With the lubricant, $\mathrm{Al}$ and $\mathrm{Zn}-\mathrm{Ni}_{2}$ coatings showed similar friction coefficients to that of $\mathrm{Cd}$ coating but $\mathrm{Zn}-\mathrm{Ni}$ coating presented a higher coefficient of friction.

Sriraman et al. [122] conducted pin-on-flat in-situ tribometry test on electrodeposited $\mathrm{Zn}-\mathrm{Ni}, \mathrm{Zn}, \mathrm{Cd}$ and $\mathrm{Cd}-\mathrm{Ti}$ coatings, and showed that $\mathrm{Zn}-\mathrm{Ni}$ coatings exhibited the best adhesive wear resistance among those studied due to the formation of a strong adherent metallic transfer film. The film formed on all coatings at the initial stage of wear test, and its stability determined the frictional characteristics of the coating, particularly in the case of providing initial lubricity to fasteners. Under unlubricated conditions, the friction coefficients of $0.47-0.55$ for low hydrogen embrittling (LHE) $\mathrm{Zn}-\mathrm{Ni}$ coatings were found to be comparable to those of $0.4-0.7$ for LHE-Cd coatings during the initial run of 500 cycles in which the transfer film was still in contact with the coating. On the other hand, $\mathrm{Zn}$ coatings exhibited higher friction coefficients of 0.8-0.85 when the transfer film was in contact with the coating, however, the friction coefficient dropped to 0.5 when the transfer film failed.

Tafreshi et al. [123] compared the tribological behaviour of electroplated $\mathrm{Zn}$ and $\mathrm{Zn}-\mathrm{Ni}$ coatings with different Ni-contents, and found that $\mathrm{Zn}-14 \mathrm{wt} . \% \mathrm{Ni}$ coatings presented the lowest wear loss and friction coefficient. Pure Zn coating had the lowest microhardness of $45 \mathrm{Hv}$, while increasing $\mathrm{Ni}$ content in the $\mathrm{Zn}-\mathrm{Ni}$ coatings from 11 to $17 \mathrm{wt} . \%$ enhanced the microhardness of the alloy coatings from 226 to $293 \mathrm{Hv}$. The increase in microhardness improved the wear resistance of the coatings to some level; however, further increase in microhardness deteriorated the wear resistance. It was found that $\mathrm{Zn}-14 \mathrm{wt} . \% \mathrm{Ni}$ coatings exhibited the best wear resistance. The mean friction coefficients of $\mathrm{Zn}, \mathrm{Zn}-11 \mathrm{wt} . \% \mathrm{Ni}, \mathrm{Zn}-14 \mathrm{wt} . \% \mathrm{Ni}$ 
and $\mathrm{Zn}-17 \mathrm{wt} . \% \mathrm{Ni}$ are $0.98,0.65,0.53$ and 0.86 , respectively. The authors explained that when the microhardness increased the real contact area between the steel pin and the coating decreased, resulting in lower friction coefficient. However, when the $\mathrm{Ni}$-content increased to $17 \mathrm{wt} . \%$, the residual stress and microcracks density increased, leading to the detachment of sections from the coating and acted as the hard third body abrasives that caused the increase of friction coefficient. Nasri et al. [124] also reported that $\mathrm{Zn}-14 \mathrm{wt}$.\%Ni coatings with fine-grained nodular morphology exhibited excellent wear resistance, offering the lowest friction coefficient compared to pure $\mathrm{Zn}$ and $\mathrm{Zn}-8 \mathrm{wt}$.\%Ni coatings.

The differences in surface morphology of $\mathrm{Zn}-\mathrm{Ni}$ coatings electrodeposited through different process parameters demonstrated different fretting and sliding wear behaviours $[125,126]$. In a fretting wear test, $\mathrm{Zn}-\mathrm{Ni}$ coatings with rough surface, which consisted of hemispherical shape of platelet agglomerates and had higher surface roughness $\left(R_{\mathrm{a}}=2.90 \mu \mathrm{m} \pm 0.35 \mu \mathrm{m}\right)$, exhibited higher wear rate from the no-slip to gross-slip conditions compared to the one with smooth surface morphology and lower surface roughness $\left(R_{\mathrm{a}}=1.35 \mu \mathrm{m}\right.$ $\pm 0.19 \mu \mathrm{m})$ [125]. The higher wear rate was due to the detachment of particles from the rough coating during sliding, resulting in larger wear scar depth. In a reciprocating pin-on-flat tribometry test performed up to 2,000 cycles under normal loads of 3.5, 7 and $12 \mathrm{~N}$, which replicated Hertzian contact stresses experienced in a fastener application for the aerospace industry, rough and porous $\mathrm{Zn}-\mathrm{Ni}$ coatings exhibited higher wear rate at lower loads (3.5 and $7 \mathrm{~N}$ ) compared to smooth and dense $\mathrm{Zn}-\mathrm{Ni}$ coatings [126]. However, when the normal load increased to $12 \mathrm{~N}, \mathrm{Zn}-\mathrm{Ni}$ coating with smooth surface experienced severe wear loss due to debonding of the coating. In contrast, the columnar structure of rough $\mathrm{Zn}-\mathrm{Ni}$ coating allowed elastic and plastic deformation at high normal loads, hence contributing to less wear loss. In terms of frictional characteristics, the formation of $\mathrm{ZnO}$ film on $\mathrm{Zn}-\mathrm{Ni}$ coatings affected the friction coefficient of the coatings. At normal load of 3.5 and $7 \mathrm{~N}$, the friction coefficient for both coatings increased to 0.85 in the initial run-in period due to the formation of a transfer film and tribofilm through flattening and wearing of the asperities. The friction coefficient then dropped to
0.5-0.55 after around 250 cycles in the steady state regime. When the normal load increased to $12 \mathrm{~N}$, the friction coefficient for both coatings remained at 0.7 in the steady state regime. The authors claimed that this could be due to the break-down and reformation of $\mathrm{ZnO}$ film at low normal loads while at high normal load the oxide film was completely broken down. The oxide film has acted as a lubricant for $\mathrm{Zn}-\mathrm{Ni}$ coating, and hence its formation is necessary for good frictional characteristics. By adding additives into a novel alkaline plating bath, Feng et al. [127] produced a bright $\mathrm{Zn-Ni}$ (13.23 wt.\%) coating that exhibited lower and more stable friction coefficient of 0.4 than $0.5-0.7$ of dull Zn-Ni (15.13 wt.\%) coatings deposited without additives. Such an improvement was attributed to the smooth and compact morphology formed when $\mathrm{Ni}$-content decreased with the addition of additives. The self-lubricating effect from the bright $\mathrm{Zn}-\mathrm{Ni}$ coating caused a relatively low friction coefficient of 0.05 in the run-in period compared to that of dull $\mathrm{Zn}-\mathrm{Ni}$ coating. The reduced surface roughness and grain size also contributed to a significant decrease in wear rate, which was about $7.95 \%$ of that of $\mathrm{Zn}-\mathrm{Ni}$ coating without additives.

$\mathrm{Zn}-\mathrm{Sn}$ coatings were first developed to replace the toxic cadmium coatings [93, 128]. They exhibit good frictional properties that are especially advantageous when applied to fasteners [85]. Sn-Zn coatings exhibited good repeatability of torque and tension characteristics without the need to apply additional post-treatment compared to $\mathrm{Zn}, \mathrm{Zn}-\mathrm{Ni}$ and $\mathrm{Zn}-\mathrm{Fe}$ coatings [129]. Dubent et al. [106] compared the friction resistance of electroplated $\mathrm{Sn}-\mathrm{Zn}$ (80-20 wt.\%) coating with electroplated $\mathrm{Cd}$ and $\mathrm{Zn}-\mathrm{Ni}$ (78-12 wt.\%) coatings after sliding friction tests. The measured values of friction coefficient were $0.11,0.14$ and 0.20 for $C d$, $\mathrm{Sn}-\mathrm{Zn}$ and $\mathrm{Zn}-\mathrm{Ni}$ coatings, respectively. The authors claimed that though the frictional coefficient of $\mathrm{Sn}-\mathrm{Zn}$ coating was comparatively higher than that of $\mathrm{Cd}$, it was still considerably low.

Esfahani et al. [61] studied the mechanically plated Zn-Sn coating (without passivation) and electroplated Al coating (with clear chromate passivation) on selfpiercing rivets before and after the joining process. The authors observed the cross-sections of riveted joints and found that the coating was much thicker near the top sheet $(22 \mu \mathrm{m} \pm 5 \mu \mathrm{m})$ than the bottom 
sheet $(2 \mu \mathrm{m} \pm 1 \mu \mathrm{m})$ (Fig. 19). The tremendous difference in thickness was attributed to the shearing phenomenon that occurred during the joining process. The piercing process had pushed the ductile coating from the lower rivet shank upward along the rivet to the top, resulting in much thicker $\mathrm{Zn}-\mathrm{Sn}$ coating near to the top sheet than the original one. On the other hand, the coating thickness of self-piercing rivet with electroplated Al coating remained unchanged $(20 \mu \mathrm{m}$ $\pm 2 \mu \mathrm{m}$ ) after the joining process. The highly adherent property of electroplated $\mathrm{Al}$ coating was due to the low surface roughness of the coating, and therefore less frictional contact, or to the electrodeposition process that is capable of depositing a coating with superior adherence to the substrate.

Ion vapour deposition is advantageous in producing corrosion resistant aluminium coatings that has no risk of hydrogen embrittlement, but the coefficient of friction for IVD-Al coating is comparatively higher than those electroplated $\mathrm{Cd}$ coatings. Ion-plated aluminium bolt and nut required approximately $60 \%$ more torque to produce the same level of tension load than that produced by Cd-electroplated ones during installation [41]. To compensate the lubricity constraint, the usage of lubricant such as cetyl alcohol is able to achieve equivalent torque-tension relationship [41]. In order to increase the frictional characteristics of ion-plated Al coatings, Zeid [130, 131] suggested alloying with lubricious element such as tin, and reported that the addition of $5 \mathrm{wt} . \%$ Sn into ion-plated $\mathrm{Al}$ to produce $\mathrm{Al}-\mathrm{Zn}$ coatings which showed slightly improved coefficient of friction with deteriorated corrosion resistant performance.

Repeated tightening and loosening of coated thread fasteners showed adverse effect on the friction coefficient and hence further influence on structural integrity [129, 132, 133]. Eccles et al. [133] reported that the head and thread friction coefficients of fasteners coated with electroplated $\mathrm{Zn}$ showed a steady increase during the first four tightening, and then became stable until the tenth tightening, at approximately twice the value of that at the initial tightening. The increase in friction coefficient was due to the breakdown of the contact surfaces, causing the wear particles to be trapped and ploughed up. Brown and Berman [24] preformed a five-cycle torque-tension test on fasteners coated with low hydrogen embrittling (LHE) electroplated $\mathrm{Zn}-\mathrm{Ni}$ coating, ion vapour deposited (IVD)-Al coating and non-aqueous electroplated-Al coating as alternatives to $\mathrm{Cd}$ coating. The results showed that IVD-Al coated fastener had the lowest lubricity while electroplated-Al started to lose its lubricity through wear after the second cycle. After five cycles of installation and removal, LHE $\mathrm{Zn}-\mathrm{Ni}$ coated fastener presented the most consistent torque-tension values. No other coating was found as lubricous as $\mathrm{Cd}$ coating, hence proper lubrication of $\mathrm{Zn}$ and $\mathrm{Zn}$-alloys electroplated fasteners is required to obtain more reliable joints in torque-controlled fastening [129]. Crotty [129] performed repeated tightening tests on $\mathrm{Zn}, \mathrm{Zn}-\mathrm{Ni}$ and $\mathrm{Zn}-\mathrm{Fe}$ plated fasteners that were treated with a yellow chromate conversion and a further posttreatment such as leachant sealant, dry lubricant, organic top-coating and organic polymer emulsion. The author found that mixture of leachant sealant with dry lubricant, as well as polymer emulsion improved the repeatability of retightening performance of the coated fasteners. Croccolo et al. [134] showed that
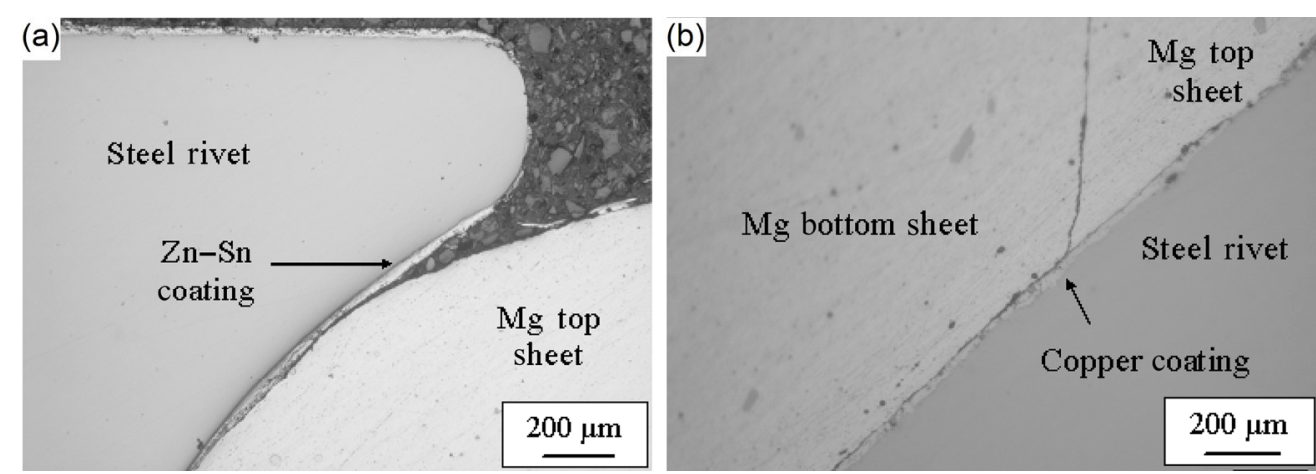

Fig. 19 Cross section images of mechanically plated $\mathrm{Zn}-\mathrm{Sn}$ rivet in a $\mathrm{Mg}$ joint (a) at the end of the rivet head in the top sheet, and (b) along the rivet shank near both top and bottom sheets. Reproduced with permission from Ref. [61], (C) Trans Tech Publications Ltd, 2012. 
solid lubricant (ceramic paste) performed more effective than oil lubricant in reducing the friction coefficient of $\mathrm{Zn}$ coated screws.

Besides the tightening factors such as tightening speed and repeated actions [133, 135], coating thickness also affects the friction coefficients and torque-tension relationships of threaded fasteners. Nassar and Zaki [136] investigated dip-coated $\mathrm{Zn}$ fasteners and reported that the thread and underhead bearing friction coefficients reduced when the coating thickness increased. The authors explained that when the coating was thin $(14-16 \mu \mathrm{m})$, the friction was caused by the interlocking of asperities, while thicker coating (20-24 $\mu \mathrm{m})$ was able to reduce the adhesion between the surfaces and thus reducing the friction.

In order to improve the corrosion resistance and frictional characteristics of the electroplated coatings, dual-layer or multi-layer coatings on fasteners were reported. Hyner and Gradowski [137, 138] proposed a multi-layer coating with $\mathrm{Ni}-\mathrm{Zn}$ alloy as the first layer, followed by $\mathrm{Zn}$ metal and lastly $\mathrm{Zn}-\mathrm{Ni}$ alloy. The authors also suggested a multi-layer coating consisted of Ni-based alloy, Zn-Ni alloy and an organic topcoat. McCauley et al. [139] suggested applying the first coating consisting of $\mathrm{Ni}$ and $\mathrm{Cr}$ to offer protective and decorative purposes while the second coating of $\mathrm{Zn}$ is for the improvement of torque-tension relationship. Offenburger et al. [140] suggested combining deposition techniques to obtain optimum properties of fasteners. The authors applied galvanized zinc coating, followed by ion vapour deposited aluminium, and reported an enhanced corrosion resistance, and most importantly the improved lubricity.

In short, $\mathrm{Cd}$ coating has been used widely on fasteners for its superior frictional characteristics, but its toxicity has induced extensive studies on its replacements. Although $\mathrm{Zn}-\mathrm{Ni}$ and $\mathrm{Zn}-\mathrm{Sn}$ have been reported as possible alternatives to $\mathrm{Cd}$, their frictional properties are still not as good as those of Cd coatings. More research of new alloy coatings with low friction coefficients to replace $\mathrm{Cd}$ coatings is highly demanded.

\section{$5 \quad$ Hydrogen embrittlement}

Hydrogen embrittlement is a catastrophic failure that happens on high strength steels, following their exposure to hydrogen and causing grain boundary fracture, even the stress applied to the high strength steels can be well below the yield strength of the steel. Hydrogen could have diffused into the substrate through aqueous or gas phase during coating deposition process and subsequently gets trapped under the coating [10]. As a result, post-electroplating heat treatment as well as heat treatment after pickling prior to hot-dip galvanizing is recommended to release the trapped hydrogen.

However, studies on post-electroplating heat treatment showed that baking is not effective in releasing the hydrogen gained during the plating process [141-143]. Failure of post-baked Zn-electroplated [141, 144], Cd-electroplated [145] and Sn-Zn-electroplated [24] fasteners due to hydrogen embrittlement is reported.

Rebak et al. [141] investigated the effect of postbaking on $\mathrm{Zn}$-electroplated automotive fasteners and reported that $86 \%$ and $75 \%$ of the hydrogen were detected in the $\mathrm{Zn}$ layer before and after baking at $204{ }^{\circ} \mathrm{C}$ for 4 hours, respectively. The authors studied the hydrogen content of three different types of steel that had gone through acid picking, electroplating and post-baking, and reported that hydrogen was picked up after the plating process, but could not be completely removed after baking. Approximately 23\% and 30\% of the hydrogen managed to escape from the bolt after 4 and 8 hours of baking, respectively, while some of the remaining hydrogen in the steel migrated even deeply into the bolt. For the non-plated bolt, the hydrogen was completely discharged after 4 hours of baking. They concluded that $\mathrm{Zn}$ coating had acted as a barrier for the discharging of hydrogen on the Zn-electroplated bolt. Hillier and Robinson [142] achieved full recovery of mechanical properties of $\mathrm{Cd}$ plated steel through baking at $200{ }^{\circ} \mathrm{C}$ for 24 hours. However, Zn-Co plated steel, which was baked at the same condition, gave incomplete recovery even when the baking duration increased to 48 hours. The authors also found that nickel and cobalt in $\mathrm{Zn}-\mathrm{Ni}$ and $\mathrm{Zn}-\mathrm{Co}$ coatings, respectively, acted as the diffusion barrier for hydrogen to penetrate into the substrate, leading to less hydrogen embrittlement as compared to pure $\mathrm{Zn}$ plated steel.

Hydrogen absorbed from electroplating process could be removed, to some extent, through post-baking. 
However, hydrogen absorption through in-service corrosion is a concern because post-baking is no longer applicable at this stage [10]. This phenomenon is called re-embrittlement and its tendency depends on the sacrificial coating, in terms of the electrochemical potential as well as the barrier properties [146, 147]. Figueroa and Robinson [147] found that electroplated $\mathrm{Zn}-\mathrm{Ni}$ coating had higher tendency to take up hydrogen from the corrosion process because of its more active potential and higher porosity as compared to electroplated $\mathrm{Cd}$ coating. However, the authors explained that not all the hydrogen generated from the corrosion process is transported and gets trapped at the crack sites, where the eventual hydrogen embrittlement occurs.

Townsend [34] studied the effect of hydrogen embrittlement on hot-dip zinc coating and indicated that pickling was not the source of hydrogen. The author reported that hydrogen was picked up during the hot-dip coating process but the intermetallic compounds had prohibited the escape of hydrogen during baking, thus causing embrittlement. Brahimi et al. [35] then validated that the fracture strength of galvanized high strength steel had deteriorated due to the trapped hydrogen. The strengths dropped by $12 \%$ and $60 \%$ as compared to the uncoated specimen based on fast fracture and increment step loading tests, respectively. Incremental step load testing is the method recommended by ASTM F1940 [148] to monitor the potential internal hydrogen embrittlement of fasteners using a notched square bar specimen. Brahimi et al. [35] concluded that the molten zinc from galvanizing process had caused thermal shock to the high strength steel, thus releasing the internally trapped hydrogen but the thick zinc coating prevented the hydrogen from escaping.

Brown and Berman [24] studied the alternative coatings to electroplated-Cd and reported that LHE electroplated-Zn-Ni, non-aqueous electroplated-Al, and IVD-aluminium coatings passed the hydrogen embrittlement test (ASTM F519) [149], while electroplated $\mathrm{Sn}-\mathrm{Zn}$ coating failed. Out of these coatings, only electroplated $\mathrm{Zn}-\mathrm{Ni}$ and $\mathrm{Sn}-\mathrm{Zn}$ coatings went through the post-plating hydrogen relief baking. Since the Al coating was electroplated in non-aqueous electrolyte, and therefore, the propensity for promoting hydrogen evolution from the electrolyte had reduced, further avoiding hydrogen embrittlement. In the re-embrittlement test, only non-aqueous electroplated-Al coating passed the test whilst both electroplated-Zn-Ni and IVD-Al coatings failed. In the re-embrittlement test, the specimens were immersed into three different operational fluids, which were reagent water (ASTM D1193) [150], synthetic sea water (ASTM D1141) [151], and 3:1 dilution propylene glycol to distilled water. The authors claimed that the excellent performance of the non-aqueous electroplated-Al coating was partly due to the barrier properties offered by its dense morphology, as seen in Fig. 9(b).

Unlike electroplating, mechanical plating is a coating process without using electrical current, and therefore, hydrogen embrittlement can be avoided or at least minimized [58]. Hydrogen may be picked up during pickling and cleaning process but with the assistance of impact media, the propensity of hydrogen absorption is reduced [58]. Hydrogen reaction does occur during mechanical plating process on the surface of the zinc particles at which the following reaction takes place:

$$
\mathrm{Zn}\left(\text { metal) }+2 \mathrm{H}^{+} \rightarrow \mathrm{H}_{2} \text { (gas) }+\mathrm{Zn}^{2+}\right. \text { (ion) }
$$

However, due to the nature of porous coatings formed, hydrogen is more likely to diffuse away from the substrate through the coating rather than getting trapped under the coating which might eventually diffuse into the substrate [58]. Therefore, post-baking after mechanical plating is not required for hydrogen relief. Coch [58] conducted stress-endurance static test on electroplated and mechanically plated stamped fasteners, and reported that none of the mechanically plated parts failed even without stress-relief baking. However, in tensile dynamic tests, the electroplated parts failed at relatively lower loads as compared to those mechanically plated. Since mechanical plating can reduce the risk of hydrogen embrittlement, this may contribute to cost reduction in the process of hydrogen embrittlement relief baking [57, 152]. However, no studies have been conducted to investigate the potential of hydrogen re-embrittlement, which may occur in-service corrosion process, of mechanically plated coatings.

In general, aqueous-based electroplating and hot-dip galvanizing induce the risk of hydrogen embrittlement 
and such risk cannot be eliminated completely through post-plating hydrogen relief baking. In contrast, it is possible to avoid hydrogen embrittlement through non-aqueous based electroplating, ion vapour deposition and mechanical plating. However, hydrogen re-embrittlement might be an issue along the in-service life, which requires further investigation.

\section{Summary}

For the coating deposition processes reviewed, processing parameters significantly affect the formation of microstructure, adhesion, porosity and surface roughness of the coatings, and therefore, further influence the corrosion resistance and frictional characteristics of the coatings. Various coating deposition techniques are compared and summarized in Table 7. Each method has its own advantages and disadvantages, depending on the desired properties and expectations. Electroplating is advantageous in forming very thin and fairly uniform coatings, but the risk of hydrogen embrittlement is unavoidable unless electroplating is done using non-aqueous electrolytes. Hot-dip galvanizing is a method that can produce comparatively thicker coatings, which consist of intermetallic phases, for use in a severely corrosive environment. However, the process temperature for this technique is high, and hence, it consumes much more energy. Similar to electroplating, hot-dip galvanizing tends to induce hydrogen embrittlement. In contrast, ion vapour deposition and mechanical plating do not present such a potential risk. Ion vapour deposition (IVD) is mainly used for depositing thin, uniform and highly adhesive aluminium coatings for applications in aerospace industry. The lubricity of IVD aluminium is low, however, and the equipment used for the process is much more expensive. Mechanical plating, on the other hand, does not require high-cost equipment investment and high processing temperature to deposit a wide range of thicknesses coatings on fasteners. However, the coatings formed are comparatively porous, less uniform and adhesive.

\section{Concluding remarks}

Thick coatings are more advantageous for applications in severely corrosive environments. Hot-dip galvanized coatings are cost effective for such thick coating productions. Recent research that focusses mostly on weight reduction has stimulated further study on improving and producing thin coatings. The crossover of the chemical cost as per coating thicknesses has shown that electroplating is more cost effective than mechanical plating if thin coating is required. However, due to the risk of hydrogen embrittlement on high steel strength fasteners, it is critical to ensure the deposition process does not induce hydrogen absorption. Ion vapour deposition (IVD) therefore has emerged as a solution to deposit thin coatings without hydrogen absorption because the process occurs under vacuum. However, the equipment for IVD is comparatively more expensive, and that is the major reason why IVD is used specifically for aerospace fasteners, which require high specific strength. Mechanical plating,

Table 7 Comparisons of fastener coating deposition methods.

\begin{tabular}{|c|c|c|c|c|}
\hline & Electroplating & Hot-dip galvanizing & Ion vapour deposition & Mechanical plating \\
\hline Types of coating & $\begin{array}{l}\text { Zn-based Al-based } \\
\text { (non-aqueous) }\end{array}$ & Zn-based & Al-based & Zn-based \\
\hline Coating thickness & $<25 \mu \mathrm{m}$ & $30-60 \mu \mathrm{m}$ & $8-25 \mu \mathrm{m}$ & $5-75 \mu \mathrm{m}$ \\
\hline Thickness uniformity & Fairly good & Moderate & Excellent & Poor \\
\hline Coating porosity & Very low & Low & Low & High \\
\hline Process temperature & $<100{ }^{\circ} \mathrm{C}$ & $435-560{ }^{\circ} \mathrm{C}$ & $100-300{ }^{\circ} \mathrm{C}$ & Room temperature \\
\hline State of process & Liquid & Liquid & Vapour & Solid \\
\hline Deposition rate & $0.1 \mu \mathrm{m} / \mathrm{min}$ & $0.8-2 \mu \mathrm{m} / \mathrm{min}$ & $2 \mu \mathrm{m} / \mathrm{min}$ & $0.5 \mu \mathrm{m} / \mathrm{min}$ \\
\hline Hydrogen embrittlement & Possible (aqueous) & Possible & No & No \\
\hline Typical industry application & Automotive, marine & Construction & Aerospace & Construction, automotive \\
\hline
\end{tabular}


hence, may be a viable solution to deposit thin coating on high strength fasteners with no risk of hydrogen embrittlement. However, further improvement of the porosity and adhesion of the coating is necessary.

The performance of coating is highly dependent on the microstructure and surface features, in particular, the frictional characteristics of fastener coatings. However, little work has been found in this area. In addition, more research is required to study the re-embrittlement effect on mechanically plated coatings, even some claimed these coatings are free from the hydrogen embrittlement.

Open Access: This article is licensed under a Creative Commons Attribution 4.0 International License, which permits use, sharing, adaptation, distribution and reproduction in any medium or format, as long as you give appropriate credit to the original author (s) and the source, provide a link to the Creative Commons licence, and indicate if changes were made.

The images or other third party material in this article are included in the article's Creative Commons licence, unless indicated otherwise in a credit line to the material. If material is not included in the article's Creative Commons licence and your intended use is not permitted by statutory regulation or exceeds the permitted use, you will need to obtain permission directly from the copyright holder.

To view a copy of this licence, visit http://creativecommons.org/licenses/ by/4.0/.

\section{References}

[1] BS 7543: 2003 Guide to durability of buildings and building elements, products and components. BSI2003.

[2] Mildenberger U, Khare A. Planning for an environmentfriendly car. Technovation 20(4): 205-214 (2000)

[3] McAuley J W. Global sustainability and key needs in future automotive design. Environ Sci Technol 37(23): 5414-5416 (2003)

[4] De Wit F M, Poulis J A. Joining technologies for automotive components. In Advanced Materials in Automotive Engineering. Rowe J, Ed. Cambridge: Woodhead Publishing, 2012: 315-329.

[5] Gould J E. Joining aluminum sheet in the automotive industry - a 30 year history. Weld J 91: 23-34 (2012)

[6] Groche P, Wohletz S, Brenneis M, Pabst C, Resch F. Joining by forming - a review on joint mechanisms, applications and future trends. J Mater Process Technol 214(10): 1972-1994 (2014)

[7] Krüger L, Mandel M. Electrochemical behaviour of aluminium/steel rivet joints. Corros Sci 53(2): 624-629 (2011)

[8] Calabrese L, Proverbio E, Pollicino E, Galtieri G, Borsellino C. Effect of galvanic corrosion on durability of aluminium/steel self-piercing rivet joints. Corros Eng, Sci Technol 50(1): 10-17 (2015)

[9] Davis J R. Forms of corrosion: Recognition and prevention. In Corrosion-Understanding the Basics. Davis J R, Ed. Ohio: ASM International, 2000: 99-192.

[10] Cottis R A. Hydrogen embrittlement. Shreir's Corros 2: 902-922 (2010)

[11] Lyons E H. Fundamental principles. In Modern Electroplating. Lowenheim F A, Ed. New York: Wiley, 1974: 31-36.

[12] Speck J A. Environmental factors and corrosion. In Mechanical Fastening, Joining, and Assembly. Boca Raton: CRC Press, 2015: 231-248.

[13] Gabe D R, Clarke M. Plated coatings. Shreir's Corros 4: 2577-2609 (2010)

[14] Singleton R, Singleton E. Fundamentals of barrel plating. Metal Finish 109(8): 14-22 (2011)

[15] Zaki N. Zinc alloy plating. In ASM Handbook, Volume 5Surface Engineering. Cotell C M, Sprague J A, Smidt Jr F A, Eds. Ohio: ASM International, 1994: 264-265.

[16] Yli-Pentti A. Electroplating and electroless plating. Compr Mater Process 4: 277-306 (2014)

[17] ASTM F1941 Standard specification for electrodeposited coatings on mechanical fasteners, inch and metric. ASTM International, 2016.

[18] Monev M, Mirkova L, Krastev I, Tsvetkova H, Rashkov S, Richtering W. Effect of brighteners on hydrogen evolution during zinc electroplating from zincate electrolytes. $J$ Appl Electrochem 28(10): 1107-1112 (1998)

[19] Casanova T, Soto F, Eyraud M, Crousier J. Hydrogen absorption during zinc plating on steel. Corros Sci 39(3): 529-537 (1997)

[20] Mirkova L, Maurin G, Krastev I, Tsvetkova C. Hydrogen evolution and permeation into steel during zinc electroplating; effect of organic additives. $J$ Appl Electrochem 31(6): 647-654 (2001)

[21] ASTM B850-98 Standard guide for post-coating treatments of steel for reducing the risk of hydrogen embrittlement. ASTM International, 1998.

[22] Wilcox G D. Electrodeposition - a versatile tool for the surface engineer. Trans IMF 85(1): 8-13 (2007)

[23] Endres F, Zein El Abedin S. Air and water stable ionic liquids in physical chemistry. Phys Chem Chem Phys 8(18): 2101-2116 (2006) 
[24] Brown S A, Berman E. Cadmium alternatives for high-strength steel. Naval Air Warfare Center Aircraft Divison Patuxent River, MD, 2011.

[25] Sato A. Zinc plating. In ASM Handbook, Volume 5-Surface Engineering. Cotell C M, Sprague J A, Smidt Jr F A, Eds. Ohio: ASM International, 1994: 227-235.

[26] Smith W J, Goodwin F E. Hot dipped coatings. In Shreir's Corros 4: 2556-2576 (2010)

[27] Wetzel D. Batch hot dip galvanized coatings. In ASM Handbook, Volume 5-Surface Engineering. Cotell C M, Sprague J A, Smidt Jr F A, Eds. Ohio: ASM International, 1994: 360-371.

[28] ASTM F2329-05 Standard specification for zinc coating, hot-dip, requirements for application to carbon and alloy steel bolts, screws, washers, nuts, and special threaded fasteners. ASTM International, 2005.

[29] Kuklík V, Kudláček J. Morphology of hot-dip galvanized coatings. In Hot-Dip Galvanizing of Steel Structures. Kuklík V, Kudláček J, Eds. Boston: Butterworth-Heinemann, 2016: 41-65.

[30] ASTM A153 Standard specification for zinc coating (Hot-Dip) on iron and steel hardware. ASTM International, 2016.

[31] Kuklík V, Kudláček J. Hot-dip galvanizing. In Hot-Dip Galvanizing of Steel Structures. Kuklík V, Kudláček J, Eds. Boston: Butterworth-Heinemann, 2016: 7-16.

[32] Marder A R. The metallurgy of zinc-coated steel. Prog Mater Sci 45(3): 191-271 (2000)

[33] Carter-Roberts P. Coatings and plating lend a hand: Special finishes are applied to threaded fasteners to prevent corrosion or enhance appearance. Assembly 2002: 64-68.

[34] Townsend H E. Effects of zinc coatings on the stress corrosion cracking and hydrogen embrittlement of low-alloy steel. Metall Trans A 6(4): 877-883 (1975)

[35] Brahimi S, Rajagopalan S, Yue S, Szpunar J. Effect of surface processing variables on hydrogen embrittlement of steel fasteners part 1: Hot dip galvanizing. Can Metall Quart 48(3): 293-301 (2009)

[36] Mahieu J, De Cooman B C, Claessens S. Galvanizability of high-strength steels for automotive applications. Metall Mater Trans A 32(11): 2905-2908 (2001)

[37] Liu H C, He Y L, Swaminathan S, Rohwerder M, Li L. Effect of dew point on the surface selective oxidation and subsurface microstructure of TRIP-aided steel. Surf Coat Technol 206(6): 1237-1243 (2011)

[38] Blumenau M, Norden M, Friedel F, Peters K. Use of pre-oxidation to improve reactive wetting of high manganese alloyed steel during hot-dip galvanizing. Surf Coat Technol 206(2-3): 559-567 (2011)

[39] Arndt M, Duchoslav J, Steinberger R, Hesser G, Commenda
C, Samek L, Arenholz E, Stifter D. Nanoscale analysis of the influence of pre-oxidation on oxide formation and wetting behavior of hot-dip galvanized high strength steel. Corros Sci 93: 148-158 (2015)

[40] Muehlberger D E. Plating with aluminum by ion vapor deposition. SAE Technical Paper 780252, 1978.

[41] Holmes V L, Muehlberger D E, Reilly J J. The substitution of IVD (Ion Vapor Deposition) aluminum for cadmium. Sprigfield: NTIS, 1989.

[42] Mattox D M. Ion plating and ion beam-assisted deposition. In Handbook of Physical Vapor Deposition (PVD) Processing. 2nd ed. Mattox D M, Ed. Norwich, NY: William Andrew Publishing, 2010: 301-331.

[43] Seer D G. Ion plating. Tribol Int 8(6): 247-251 (1975)

[44] Mattox D M. Ion plating_past, present and future. Surf Coat Technol 133-134: 517-521 (2000)

[45] Ahmed N A G. Ion plating: Optimum surface performance and material conservation. Thin Solid Films 241(1-2): 179-187 (1994)

[46] Ahmed N A G, Teer D G. A simple and inexpensive rotating barrel to ion plate small components. J Phys E: Sci Instrum 17(5): 411-416 (1984)

[47] Lee Holmes V, Bridger M. Aluminum coatings turn green: IVD process delivers environmentally friendly corrosionprotection. Metal Finish 102(12): 6-10 (2004)

[48] Steube K E. Glow discharge-tumbling vapor deposition apparatus. U. S. Patent US3926147A, Dec. 1975.

[49] Roberge P R. Protective coatings. In Handbook of Corrosion Engineering. Roberge P R, Ed. New York: McGraw-Hill, 2012: 787-867.

[50] Lee Holmes V, Bridger M. IVD aluminum coating and application of the process at boeing-St. Louis.

[51] McCune R C, Forsmark J H, Upadhyay V, Battocchi D. Characterization of coatings on steel self-piercing rivets for use with magnesium alloys. In Magnesium Technology 2015. Manuel M V, Singh A, Alderman M, Neelameggham N R, Eds. Cham: Springer, 2015: 327-332.

[52] Clayton E T. Method for bright metal plating. U. S. Patent US2640001A, May 1953.

[53] Satow A. Mechanical plating. In ASM Handbook, Volume 5-Surface Engineering. Cotell C M, Sprague J A, Smidt Jr F A, Eds. Ohio: ASM International, 1994: 330-332.

[54] Cutcliffe J E. Metal plating by a wet mechanical process. U. S. Patent US3443985A, May 1969.

[55] Mechanical plating starts to take over from electroplating. Prod Eng 61(6): 39-41 (1982)

[56] Michael G. Process of plating metal objects. U. S. Patent US3400012A, Sep. 1968.

[57] Allison G M. Mechanical plating. Metal Finish 100 Suppl 1: 
384-393 (2002)

[58] Coch L. Plating fasteners, avoiding embrittlement. Prod Finish (Cincinnati) 51(8): 56-62 (1987)

[59] Coch L. Non-polluting system for metal surface treatments. U. S. Patent US4162680A, Jul. 1979.

[60] Wang S M, He M Y, Zhao X J, Peng Z H, Liu L. Microstructures and key properties of mechanically deposited Zn-Al coatings. Chin J Mech Eng 22(4): 608-613 (2009)

[61] Esfahani M, Durandet Y, Wang J, Wong Y C. Effect of joining process on the coatings of self-piercing rivets. $A d v$ Mater Res 488-489: 1501-1505 (2012)

[62] Elshennawy A K, Weheba G S. Other surface enhancement processes. In Manufacturing Processes and Materials. Dearborn: Society of Manufacturing Engineers (SME), 2015: 613-627.

[63] Sequeira C A C, Pacheco A M G, Nunes C M G S. Formation of diffusion coatings on iron and steel: 3 aluminium, chromium, and zinc coatings. Surf Eng 4(1): 65-81 (1988)

[64] Sriraman K R, Brahimi S, Szpunar J A, Osborne J H, Yue S. Characterization of corrosion resistance of electrodeposited Zn-Ni Zn and Cd coatings. Electrochim Acta 105: 314-323 (2013)

[65] Taniguchi T, Saito H, Yamada M, Iobe H, Takada K, Yoshida M, Sato E, Ishihara T. Zn-Ni plating as a cadmium alternative. SAE Technical Papers 2007-01-3837, 2007.

[66] Jordan C E, Marder A R. Fe-Zn phase formation in interstitialfree steels hot-dip galvanized at $450{ }^{\circ} \mathrm{C}$ : Part I $0.00 \mathrm{wt} \%$ Al-Zn baths. J Mater Sci 32(21): 5593-5602 (1997)

[67] Guttmann M. Diffusive phase transformations in hot dip galvanizing. Mater Sci Forum 155-156: 527-548 (1994)

[68] Jordan C E, Marder A R. Fe-Zn phase formation in interstitialfree steels hot-dip galvanized at $450{ }^{\circ} \mathrm{C}$ : Part II $0.20 \mathrm{wt} \%$ Al-Zn baths. J Mater Sci 32(21): 5603-5610 (1997)

[69] Yadav A P, Katayama H, Noda K, Masuda H, Nishikata A, Tsuru T. Effect of Fe-Zn alloy layer on the corrosion resistance of galvanized steel in chloride containing environments. Corros Sci 49(9): 3716-3731 (2007)

[70] Mackowiak J, Short N R. Metallurgy of galvanized coatings. Int Met Rev 24(1): 1-19 (1979)

[71] Townsend H E. Continuous hot dip coatings. In ASM Handbook, Volume 5-Surface Engineering. Cotell C M, Sprague J A, Smidt Jr F A, Eds. Ohio: ASM International, 1994: 339-348.

[72] Su X P, Xu P, Liu Y, Wang J H, Tu H, Wu C J, Peng H P. Mathematical modeling and numerical simulation of layer growth and phase transformation during galvannealing process. Surf Coat Technol 206(23): 5012-5021 (2012)

[73] Lu J. Appearance of the mechanical plating formed by $\mathrm{Zn}-\mathrm{Al}$ compounding flake powders and its anticorrosion. Adv Mater Res 79-82: 811-814 (2009)
[74] Cook P C, Cook S N, Murray M T. Alloy coated workpieces. U. S. Patent US9885103B2, Feb. 2018.

[75] Chung P P, Cook P, Wang J, Durandet Y. Effects of heat treatment on mechanically plated $\mathrm{Zn}$-Sn coating and its corrosion performance. In Proceedings of Corrosion and Prevention 2018, Adelaide, Australia, 2018.

[76] Brown C J, Smith M W, Youngblood D, Zeng L, Haylock L, Gurrola B, Moran J P. Evaluation of alternatives to electrodeposited cadmium for threaded fastener applications (II). SAE Technical Papers 2009-01-3228, 2008.

[77] Brown C J, Smith M W, Zeng L, Haylock L, Gurrola B, Youngblood D. Evaluation of alternatives to electrodeposited cadmium for threaded fasteners applications (III). SAE Technical Papers 2009-01-3228E, 2009.

[78] Gallego A, Gil J F, Vico J M, Ruzzante J E, Piotrkowski R. Coating adherence in galvanized steel assessed by acoustic emission wavelet analysis. Scr Mater 52(10): 1069-1074 (2005)

[79] Song G M, Sloof W G. Effect of alloying element segregation on the work of adhesion of metallic coating on metallic substrate: Application to zinc coatings on steel substrates. Surf Coat Technol 205(19): 4632-4639 (2011)

[80] Shibli S M A, Manu R. Process and performance improvement of hot dip zinc coating by dispersed nickel in the under layer. Surf Coat Technol 197(1): 103-108 (2005)

[81] Shibli S M A, Manu R, Dilimon V S. Effect of nickel-rich barrier layer on improvement of hot-dip zinc coating. Appl Surf Sci 245(1-4): 179-185 (2005)

[82] Song G M, Vystavel T, Van Der Pers N, De Hosson J T M, Sloof W G. Relation between microstructure and adhesion of hot dip galvanized zinc coatings on dual phase steel. Acta Mater 60(6-7): 2973-2981 (2012)

[83] Mattox D M. Interface Formation and the Adhesion of Deposited Thin Films. Albuquerque, NM: Sandia Corp, 1965.

[84] Ahmed N A G. Ion plated aluminium coatings for the corrosion protection of steel. Anti-Corros Methods Mater 31(12): 4-8 (1984)

[85] Chrysanthou A. Corrosion behaviour of self-piercing riveted joints. In Self-Piercing Riveting: Properties, Processes and Applications. Chrysanthou A, Sun X, Eds. Cambridge: Woodhead Publishing, 2014: 41-55.

[86] Wang S M, He M Y, Zhao X J. Bonding mechanism of mechanically deposited coating/substrate. Phys Procedia 50: 315-321 (2013)

[87] Ding J C. Study on the forming process of mechanical zinc plating. Adv Sci Lett 4(3): 1165-1169 (2011)

[88] Davis J R. Corrosion control by protective coatings and inhibitors. In Corrosion-Understanding the Basics. Davis J R, Ed. Ohio: ASM International, 2000: 363-406. 
[89] Ingle M W. Cadmium elimination in surface engineering. In ASM Handbook, Volume 5-Surface Engineering. Cotell C M, Sprague J A, Smidt Jr F A, Eds. Ohio: ASM International, 1994: 918-924.

[90] Zhang X G. Corrosion of zinc and zinc alloys. In $A S M$ Handbook, Volume 13B-Corrosion: Materials. Cramer S D, Covino Jr B S, Eds. Ohio: ASM International, 2005: 402-417.

[91] Garcia R, Barboza J. Coating trends for fasteners. SAE Technical Papers 1999-01-3072, 1999.

[92] Shaw B A, Shaw W W, Schmidt D P. Corrosion of metallic coatings. In ASM Handbook, Volume 13C-Corrosion: Environments and Industries. Cramer S D, Covino Jr B S, Eds. Ohio: ASM International, 2006: 61-68.

[93] Wilcox G D, Gabe D R. Electrodeposited zinc alloy coatings. Corros Sci 35(5-8): 1251-1258 (1993)

[94] Crotty D. Zinc alloy plating for the automotive industry. Met Finish 94(9): 54, 56-58 (1996)

[95] Ramanauskas R, Quintana P, Maldonado L, Pomés R, PechCanul M. Corrosion resistance and microstructure of electrodeposited $\mathrm{Zn}$ and $\mathrm{Zn}$ alloy coatings. Surf Coat Technol 92(1-2): 16-21 (1997)

[96] Budman E, Sizelove R R. Zinc alloy plating. Met Finish 100 Suppl 1: 320-325 (2002)

[97] Yang Z N, Zhang Z, Zhang J Q. Electrodeposition of decorative and protective $\mathrm{Zn}-\mathrm{Fe}$ coating onto low-carbon steel substrate. Surf Coat Technol 200(16-17): 4810-4815 (2006)

[98] Hegde A C, Venkatakrishna K, Eliaz N. Electrodeposition of $\mathrm{Zn}-\mathrm{Ni}, \mathrm{Zn}-\mathrm{Fe}$ and $\mathrm{Zn}-\mathrm{Ni}-\mathrm{Fe}$ alloys. Surf Coat Technol 205(7): 2031-2041 (2010)

[99] Fratesi R, Roventi G. Corrosion resistance of Zn-Ni alloy coatings in industrial production. Surf Coat Technol 82(1-2): 158-164 (1996)

[100] Gavrila M, Millet J P, Mazille H, Marchandise D, Cuntz J M. Corrosion behaviour of zinc-nickel coatings, electrodeposited on steel. Surf Coat Technol 123(2-3): 164-172 (2000)

[101] Byk T V, Gaevskaya T V, Tsybulskaya L S. Effect of electrodeposition conditions on the composition, microstructure, and corrosion resistance of $\mathrm{Zn}-\mathrm{Ni}$ alloy coatings. Surf Coat Technol 202(24): 5817-5823 (2008)

[102] Fratesi R, Roventi G, Branca C, Simoncini S. Corrosion resistance of Zn-Co alloy coatings. Surf Coat Technol 63(1-2): 97-103 (1994)

[103] Fratesi R, Roventi G, Giuliani G, Tomachuk C R. Zinccobalt alloy electrodeposition from chloride baths. J Appl Electrochem 27(9): 1088-1094 (1997)

[104] Ashiru O A, Shirokoff J. Electrodeposition and characterization of tin-zinc alloy coatings. Appl Surf Sci 103(2): 159-169 (1996)
[105] Kuehnl W, Mauer D, Opper R. Vehicle body component with a tin/zinc coating. U. S. Patent US6308544B1, Oct. 2001.

[106] Dubent S, Mertens M L A D, Saurat M. Electrodeposition, characterization and corrosion behaviour of Tin-20 wt.\% zinc coatings electroplated from a non-cyanide alkaline bath. Mater Chem Phys 120(2-3): 371-380 (2010)

[107] Lodhi Z F, Tichelaar F D, Kwakernaak C, Mol J M C, Terryn H, De Wit J H W. A combined composition and morphology study of electrodeposited $\mathrm{Zn}-\mathrm{Co}$ and $\mathrm{Zn}-\mathrm{Co}-\mathrm{Fe}$ alloy coatings. Surf Coat Technol 202(12): 2755-2764 (2008)

[108] Lodhi Z F, Mol J M C, Hovestad A, 't Hoen-Velterop L, Terryn H, De Wit J H W. Corrosion resistance of $\mathrm{Zn}-\mathrm{Co}-\mathrm{Fe}$ alloy coatings on high strength steel. Surf Coat Technol 203(10-11): 1415-1422 (2009)

[109] Hyner J, Lewis B S. Multi-layer corrosion resistant coating for fasteners and method of making. U. S. Patent US5275892A, Jan. 1994.

[110] Mechanical plating with tin-cadmium alloy. Anti-Corros Methods Mater 25(3): 8-9 (1978)

[111] Eriksson H E A, Kaberg B S, Rehnovist N T. Process of zinc coating fasteners. U. S. Patent US4092224A, May 1978.

[112] Ahmed N A G. Ion vapour deposition of aluminium for corrosion protection: 10 years production experience. Surf Eng 2(2): 95-102 (1986)

[113] Teer D G, Abu Zeid O A. Al-Zn coatings for the corrosion protection of steel. Thin Solid Films 72(2): 291-296 (1980)

[114] Moore J F. Mechanical plating - the impact process to avoid embrittlement. J Mech Working Technol 10(2): 243-245 (1984)

[115] Grunwald J J, Klein I, Whitmore B. Mechanical plating with oxidation-prone Metals. U. S. Patent US4800132A, Jan. 1989.

[116] Coch L G, Satow A. Process for plating adherent Co-deposit of aluminum, zinc, and tin onto metallic substrates, and apparatus. U. S. Patent US4880132A, Nov. 1989.

[117] Bartlett I, Long E, Rowan A, Wall A. Mechanical plating of zinc alloys. U. S. Patent US0182337, Dec. 2002.

[118] Zhao X J, He M Y, Liu L, Wang S M, Peng Z H, Chang F. Deposition activator for mechanical plating of $\mathrm{Zn}$-Sn alloy. CN Patent 102409335B, Sep. 2013.

[119] Chandak P, Katti R K, Raina S. Fastener coating change for efficient functional performance in automotive application. SAE Technical Papers 2013-01-2899, 2013.

[120] Holmberg K, Erdemir A. Influence of tribology on global energy consumption, costs and emissions. Friction 5(3): 263-284 (2017)

[121] Zeng L, Monserratt E, Haylock L, Gurrola R H, Youngblood 
D, Brown C J, Smith M W. Evaluation of alternatives to electrodeposited cadmium for threaded fastener applications. SAE Technical Papers 2006-01-3169, 2006.

[122] Sriraman K R, Strauss H W, Brahimi S, Chromik R R, Szpunar J A, Osborne J H, Yue S. Tribological behavior of electrodeposited $\mathrm{Zn}, \mathrm{Zn}-\mathrm{Ni}, \mathrm{Cd}$ and $\mathrm{Cd}-\mathrm{Ti}$ coatings on low carbon steel substrates. Tribol Int 56: 107-120 (2012)

[123] Tafreshi M, Allahkaram S R, Farhangi H. Comparative study on structure, corrosion properties and tribological behavior of pure $\mathrm{Zn}$ and different $\mathrm{Zn}-\mathrm{Ni}$ alloy coatings. Mater Chem Phys 183: 263-272 (2016)

[124] Nasri F, Zouari M, Kharrat M, Dammak M, Vacandio F, Eyraud M. Structural, micromechanical and tribological characterization of $\mathrm{Zn}-\mathrm{Ni}$ Coatings: Effect of sulfate bath composition. Trans Indian Inst Met 71(8): 1827-1840 (2018)

[125] Lee L, Régis É, Descartes S, Chromik R R. Fretting wear behavior of Zn-Ni alloy coatings. Wear 330-331: 112-121 (2015)

[126] Lee L, Behera P, Sriraman K R, Chromik R R. The effect of contact stress on the sliding wear behaviour of $\mathrm{Zn}-\mathrm{Ni}$ electrodeposited coatings. Wear 400-401: 82-92 (2018)

[127] Feng Z B, Ren L L, Zhang J Q, Yang P X, An M Z. Influence of additives on microstructure, mechanical and tribological properties of nanocrystalline $\mathrm{Zn}-\mathrm{Ni}$ coatings in a novel alkaline bath. RSC $A d v$ 6(48): 42029-42040 (2016)

[128] Asher R K. Tin alloy plating. In ASM Handbook, Volume 5-Surface Engineering. Cotell C M, Sprague J A, Smidt Jr F A, Eds. Ohio: ASM International, 1994: 258-263.

[129] Crotty D. Torque and tension control for automotive fasteners. Met Finish 97(5): 44-50 (1999)

[130] Abu-Zeid O A. Tribology and corrosion of Al-1.5wt.\%Zn5wt.\%Sn ion platings. Wear 139(2): 313-318 (1990)

[131] Abu Zeid O A. Influence of tin addition on corrosion resistance of aluminium ion platings. Br Corros $J$ 27(2): 144-146 (1992)

[132] Jiang Y Y, Zhang M, Park T W, Lee C H. An experimental investigation on frictional properties of bolted joints, In: Proceedigns of ASME 2002 Pressure Vessels and Piping Conference, Vancouver, BC, Canada, 2002: 59-66.

[133] Eccles W, Sherrington I, Arnell R D. Frictional changes during repeated tightening of zinc plated threaded fasteners. Tribol Int 43(4): 700-707 (2010)

[134] Croccolo D, De Agostinis M, Fini S, Olmi G. Tribological properties of bolts depending on different screw coatings and lubrications: An experimental study. Tribol Int 107: 199-205 (2017)

[135] Nassar S A, Ganeshmurthy S, Ranganathan R M, Barber G C. Effect of tightening speed on the torque-tension and wear pattern in bolted connections. J Pressure Vessel Technol
129(3): 426-440 (2007)

[136] Nassar S A, Zaki A M. Effect of coating thickness on the friction coefficients and torque-tension relationship in threaded fasteners. J Tribol 131(2): 021301 (2009)

[137] Hyner J, Gradowski S. Multi layer corrosion resistant coating. U. S. Patent US4746408A, May 1988.

[138] Hyner J, Gradowski S. Corrosion resistant coating for fasteners. U. S. Patent US4837090A, Jun. 1989.

[139] McCauley L D, Lanham T R, Notaro D F. Dual plated fasteners. U.S. Patent US6599071B1, Jul. 2003.

[140] Offenburger M, Parker E, Ptak F. Threaded fastener. U.S. Patent US4802807A, Feb. 1989.

[141] Rebak R B, Muchjin L, Szklarska-Smialowska Z. Hydrogen diffusion and accumulation in automotive fasteners. Corrosion 53(6): 481-488 (1997)

[142] Hillier E M K, Robinson M J. Hydrogen embrittlement of high strength steel electroplated with zinc-cobalt alloys. Corros Sci 46(3): 715-727 (2004)

[143] Lonyuk B, Hop R, Hanlon D N, Van Der Zwaag S, Zuidema J, Bakker A. A study of post plating heat treatment in automotive fastener steels. In ECF14, Cracow, 2002.

[144] Ferraz M T, Oliveira M. Steel fasteners failure by hydrogen embrittlement. Ciênc Tecnol Mater 20(1-2): 128-133 (2008)

[145] Jha A K, Narayanan P R, Sreekumar K, Mittal M C, Ninan $\mathrm{K} N$. Hydrogen embrittlement of $3.5 \mathrm{Ni}-1.5 \mathrm{Cr}-0.5 \mathrm{Mo}$ steel fastener. Eng Fail Anal 15(5): 431-439 (2008)

[146] Chalaftris G, Robinson M J. Hydrogen re-embrittlement of high strength steel by corrosion of cadmium and aluminium based sacrificial coatings. Corros Eng, Sci Technol 40(1): 28-32 (2005)

[147] Figueroa D, Robinson M J. The effects of sacrificial coatings on hydrogen embrittlement and re-embrittlement of ultra high strength steels. Corros Sci 50(4): 1066-1079 (2008)

[148] ASTM F1940-07a Standard test method for process control verification to prevent hydrogen embrittlement in plated or coated fasteners. ASTM International, 2007.

[149] ASTM F519-18 Standard test method for mechanical hydrogen embrittlement evaluation of plating/coating processes and service environments. ASTM International, 2018.

[150] ASTM D1193-06 Standard specification for reagent water. ASTM International, 2018.

[151] ASTM D1141-98 Standard practice for the preparation of substitute ocean water. ASTM International, 2003.

[152] Timms J, Wynn P C. Mechanical plating. Prod Finish (Cincinnati) 66(1): 74-79 (2001) 


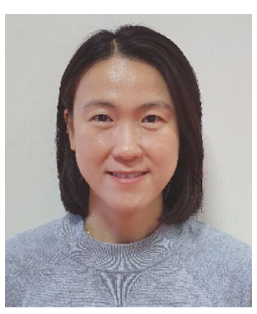

Ping Ping CHUNG. She received her bachelor degree in mechanical \& materials engineering from University of Technology Malaysia (Malaysia) and master degree in materials engineering from Loughborough University (United

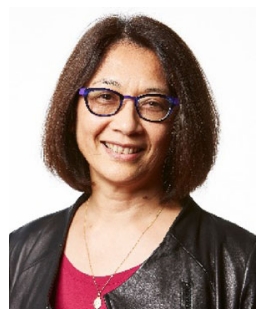

Yvonne DURANDET. She received her bachelor degree in mechanical engineering from SUPMECA (France) and Ph.D. degree in materials engineering from the University of Adelaide (Australia). After more than 10 years at BHP Melbourne Research Laboratories, she joined Swinburne University of Technology to work on cooperative research projects
Kingdom). She worked as a corrosion engineer in Corus Strip Products, UK for 3 years. After that, she worked as an academic staff in Swinburne University of Technology Sarawak Campus (Malaysia) for 5 years. She is currently a Ph.D. student at Swinburne University of Technology (Australia). Her research interests cover surface engineering and corrosion.

with industry. Her current position is senior lecturer (advanced manufacturing) in the Department of Mechanical and Product Design Engineering and academic director (Industry Engagement) in the Faculty of Science, Engineering \& Technology, at Swinburne University of Technology. Her research interests cover near net shape manufacturing, surface engineering, laser processing of materials and advanced joining. 